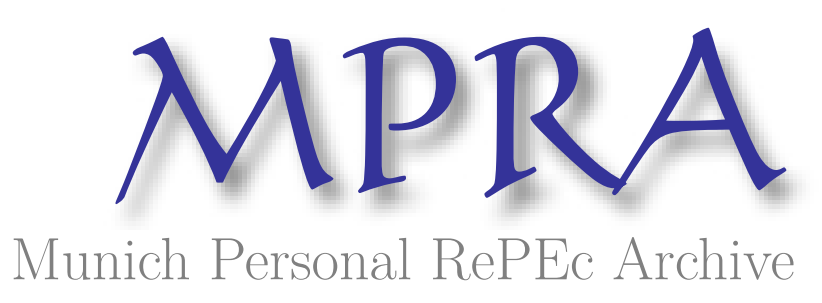

\title{
Delayed Collection of Unemployment Insurance in Recessions
}

Xie, Zoe

Federal Reserve Bank of Atlanta

15 June 2019

Online at https://mpra.ub.uni-muenchen.de/99914/

MPRA Paper No. 99914, posted 04 May 2020 11:27 UTC 


\title{
Delayed Collection of Unemployment Insurance in Recessions
}

\author{
Zoe Xie*
}

\begin{abstract}
Using variations in UI policies over time and across U.S. states, this paper provides evidence that allowing unemployed workers to delay the collection of benefits increases their job-finding rate. In a model with discrete job take-up decisions, benefit entitlement, wage-indexed benefits, and heterogeneous job types, I demonstrate that the policy can increase an unemployed worker's willingness to work, even though more benefits in general reduce the relative value of employment. In a calibrated quantitative model, I find that allowing delayed benefit collection increases the overall job finding rates and may lower unemployment rate both in a steady state stationary economy and over a transition path during 2008-2012.
\end{abstract}

Keywords: Unemployment insurance; Social program design; Great recession

JEL classifications: E24, J65

\footnotetext{
*Affiliation: Federal Reserve Bank of Atlanta. Email: xiexx196@gmail.com. First version: November 2015. This version: May 2019. The author would like to thank Ashley Edwards and Lewis Warren at the U.S. Census Bureau for answering questions about the SIPP 2008 panel. Suggestions from the editor, the associate editor, and two anonymous referees are greatly appreciated. The initial draft of this paper was completed with the financial support of the University of Minnesota Doctoral Dissertation Fellowship, and benefited from discussions with Víctor Ríos-Rull, Jonathan Heathcote, Sam Schuhlhofer-Wohl, Si Guo, and Naoki Takayama. Deepmala Pokhriyal provided excellent research assistance. The views expressed in this paper are those of the authors and do not necessarily represent the views of the Federal Reserve System or the Federal Reserve Banks.
} 


\section{INTRODUCTION}

A common assumption in the literature on unemployment insurance (UI) policy is that once an unemployed worker finds a job, she loses any uncollected benefits. This assumption does not, however, always hold. During recessions, the "retention policy" in the U.S. allows workers to delay the collection of existing UI benefits to future unemployment spells. This policy encourages unemployed workers to take up short-term low-paying jobs without worrying about low or zero benefits and reduced consumption in future unemployment spells. To the extent that the policy helps smooth consumption between two unemployment spells, it potentially reduces the cost of unemployment for risk averse individuals.

In this paper, I first empirically document that during recessions workers in the U.S. can and do delay the collection of UI benefits to future unemployment spells. There are differences both across states and over time in how easily an unemployed worker can delay collection of leftover benefits. Exploiting these differences, I find evidence that during the most recent recession, easier delayed benefit collection induced unemployed workers to take up jobs sooner. Intuitively, because UI benefits are proportional to wage income, low-paying jobs qualify for lower benefits. Thus, an unemployed worker has less incentive to take a low-paying or short-term job because of low future benefits when she becomes unemployed again. With the retention policy, if the worker has leftover benefits when she starts a job, she can delay the collection to future unemployment spells.

Motivated by this evidence, I extend the canonical McCall (1970) framework to incorporate features of the retention policy. In particular, suppose jobs arrive exogenously, and each period unemployed workers decide whether to accept a job and start working the next period. Employed workers may qualify for UI benefits through working. If a newly unemployed worker qualifies for benefits, she receives a fixed amount of benefits each period for a finite number of periods. The level of benefits received each period is proportional to the worker's wages prior to unemployment.

Absent the retention policy once an unemployed worker finds a job, any uncollected benefits are forfeited. With the retention policy, the uncollected benefits stay on the worker's record, and when she becomes unemployed again she can choose between any newly qualified UI benefits and the leftover benefits. ${ }^{1}$ By giving the worker a choice in future benefits, the retention policy increases the expected value of employment by (weakly) increasing the value of future unemployment. With the retention policy, the unemployed workers take up jobs sooner, and the aggregate job-finding rate is higher. ${ }^{2}$

\footnotetext{
${ }^{1}$ As an example, suppose a worker qualifies for 26 weeks of benefits of $\$ 200$ per month. He finds a job after collecting benefits for 6 weeks. Without the retention policy, he loses the 20 weeks of benefits, and whether he qualifies for benefits when he becomes unemployed again depends on how much he works between the two unemployment spells. With the retention policy, if he does not qualify for new benefits when he becomes unemployed again, he can continue collecting the 20 weeks of benefits. If he qualifies for new benefits, then he can choose between the leftover 20 weeks of old benefits and the newly qualified benefits.

${ }^{2} \mathrm{~A}$ key assumption here is that workers do not quit into unemployment. This assumption is supported by the fact that in the U.S. workers who quit typically are not eligible to collect UI benefits, although quits are sometimes hard
} 
The impact of the retention policy on the unemployed worker's job take-up decision depends on three factors. First, the effect is larger when the offered job has a shorter expected job tenure (such as a temp job). When the worker expects a job to end sooner, her income during the subsequent unemployment is more important. Since the retention policy affects the value of her future unemployment, its impact on her current job decision is stronger when the offered job has a shorter expected tenure. Second, the effect of the retention policy is larger when the difference in wages between previous and future jobs is (positive) larger. A positive wage difference means that the current UI benefits are higher than the expected future benefits. The larger the wage difference, the larger the difference between current and future benefits, and the more retention policy raises the value of employment for unemployed workers. The retention policy is hence more likely to affect the decision to take a low wage job. Third, the effect is larger when the benefit duration is longer such as with UI extensions during a recession. A longer UI entitlement gives the unemployed worker more leftover benefits to carry over to a future unemployment spell, thus increasing the effect of the retention policy.

To evaluate the effect of the retention policy on the aggregate job finding rate and unemployment rate, both at the steady state and over the transition, I calibrate the model steady states using data on the wage distribution and the distribution of wage changes between pre- and post-unemployment work derived from the Survey of Income Program Participation (SIPP) panels. In a (stationary) steady state resembling 2012, consistent with the intuitions, the retention policy induces unemployed workers to accept low-paying or short-tenured jobs sooner, and as a result the overall job finding rate is higher. The effect on the unemployment rate is ambiguous, depending on the relative size of the increase in job finding rate and the shift of workers into short-duration jobs. The aggregate impacts are similar over a transition during 2008-2012.

This paper contributes to the understanding of how UI policy affects unemployed workers' job search behavior. Previous literature has studied how benefit level and benefit duration affect search. Empirical evidence in the literature suggests that more generous UI benefits are associated with longer spells of unemployment; see Krueger and Meyer (2002) for a survey of the earlier literature. ${ }^{3}$ I find that because of the retention policy in recessions, higher benefit levels or longer benefit durations do not necessarily mean lower job finding probabilities. In fact, higher expected benefits in future unemployment spells may increase the job finding probability of current unemployed workers. ${ }^{4}$

to distinguish from other reasons of unemployment; see, for example, Zhang and Faig (2012). In Section 5 I relax this assumption and allow workers to quit into unemployment and still eligible to collect unemployment benefits. The results are similar to the baseline results without the option to quit.

${ }^{3}$ More recently, Krueger and Mueller (2010) use time use data to find that for a subgroup of benefit-eligible unemployed workers, more generous benefits reduce their job search time. At the same time, they find that search activity of the benefit-eligible unemployed spikes as benefit exhaustion (26 weeks) approaches, which suggests that longer UI duration is associated with less search by the unemployed workers.

${ }^{4}$ Because the effect of the retention policy requires that workers form expectation about future benefits, government commitment to these expected future benefits is implicitly assumed. Pei and Xie (2016) examines the effects of government commitment to future policies on the optimal UI benefits over business cycles. 
Another strand of the literature looks at specific policy details and studies how they affect search behavior. For example, Zhang and Faig (2012) examine how endogenous UI eligibility affects search, and find that when UI benefits must be earned with employment, generous UI becomes an additional benefit to working. The current paper complements their work by incorporating a form of endogenous eligibility and wage-indexed benefits, so that working at a high-paying job has the additional benefit of potentially qualifying for higher benefits in unemployment. With the retention policy, this benefit extends into future unemployment spells.

Because the effect of the retention policy is more quantitatively relevant during recessions when the maximum potential UI duration is extended, the study of the retention policy has implications for the optimal cyclical UI policy; see, for example, Jung and Kuester (2015), and Mitman and Rabinovich (2015). As the retention policy changes with the scale of UI extensions, incorporating the retention policy in models evaluating the UI extensions will affect the quantitative results. In fact, quantitatively I find that the retention policy mitigates the adverse effect of UI extensions. ${ }^{5}$

The rest of the paper proceeds as follows. Section 2 describes the policy background and presents empirical evidence pertaining to policy variations. Section 3 uses a simple model to illustrate the effect of the retention policy. Section 4 presents a quantitative model and analysis based on calibrated parameters. Section 5 discusses extensions to the baseline quantitative model. Results of these extensions are included in Appendix D. Section 6 concludes.

\section{Policy Background and Empirical Evidence}

\subsection{Background on retention policy}

The U.S. retention policy allows unemployed workers to delay collection of UI benefits to future unemployment spells. ${ }^{6}$ Two important ingredients here are that workers qualify for benefits through work - so not all unemployed workers receive benefits - and the monthly benefit payout amount ("benefit level") is proportional to wages received during the most recent employment. The retention policy changes over time. In addition, while the majority of states have the retention policy, states differ in how easy it is for unemployed workers to take advantage of the retention policy.

Policy variations over time During normal times, when the maximum potential UI duration is 26 weeks, an unemployed worker has up to one year ("benefit collection window") to use all 26 weeks. As an example, an unemployed worker who qualifies for 26 weeks of benefits and starts collecting on January 1, 2005 may collect during anytime before January 1, 2006. During this time, if she finds a

\footnotetext{
${ }^{5}$ See, for example, Fujita (2010), Rothstein (2011), Nakajima (2012), Hagedorn et al. (2015), and Chodorow-Reich et al. (2018) for evaluations of the impact of UI extensions in recessions.

${ }^{6}$ This section focuses on explaining the variations over time and across states in the retention policy and abstracts from the variations in UI extensions. While UI extensions also vary over time in recessions, it does not affect the cross-sectional empirical analysis. The variations across states are controlled for in the empirical analysis by taking data from a time when states in the sample implemented roughly the same length of UI extensions.
} 
job after collecting benefits for 13 weeks, then she may collect the other 13 weeks if she loses her job again before January 1, 2006. A complication arises if the employment during this one-year period qualifies her for a new UI segment. When this happens, the worker may choose whether to continue collecting the 13 weeks left over from before, or start the new UI segment. However, she may not keep both UI segments.

The retention policy plays a more important role in recessions for three reasons. First, the benefit collection window is extended with UI benefit extensions such as during the Great Recession when the UI benefits were extended from 26 to over 90 weeks. With these extensions, the benefit collection window is also extended from one year to as long as the extensions are in effect. For example, during the Great Recession, extensions were in effect for four years (from 2008 to the end of 2013). Second, long-term jobs are harder to find in a recession. With short-term employment, it is more likely that at the end of a job the worker is still within the collection window of the benefit that she started before taking the job.

Third, the opportunity to choose between leftover benefits and new UI segment makes a difference if the benefit level is high enough on the leftover benefits that the workers will choose the leftover benefits. Jobs before the start of the recession likely qualify for higher benefits than jobs during a recession. This is true if during the recession a worker is forced to take a job that pays much less than her job before the recession. ${ }^{7}$

I therefore focus on the effects of the retention policy during recessions. ${ }^{8}$ It is worth noting that unlike during normal times when the worker can choose between leftover benefits and newly qualified benefits, in recessions, the retention policy is more restrictive on choice. In particular, once the worker qualifies for new benefits, she may not continue collecting any leftover benefits from before. This restriction was in place until July 2010, when a federal legislation awarded the choice of UI segments to the unemployed worker. ${ }^{9}$

Policy variations across U.S. states In addition to variations over time, the retention policy also differs across states. In particular, states differ in how much work is needed to re-qualify for a new UI segment when the worker already has an open UI segment. Most states require a worker to

\footnotetext{
${ }^{7}$ As an example, suppose a worker is laid off from a regular, long-term job at General Electric and cannot find a similar job during the recession. She is then forced to work at a temporary job at McDonald's. The two jobs potentially differ in two dimensions - wages and job security. Wages are likely higher at General Electric, and job security is likely worse at McDonald's especially if the job is temporary. Because of lower wages, if the worker qualifies for new UI benefits at McDonald's, the new benefit level is lower than her benefits after working at General Electric. At the same time, because of shorter job tenure, the job at McDonald's may not qualify for new UI benefits, in which case being able to continue collecting any leftover benefits will be even more valuable.

${ }^{8}$ For tractability, in the model I assume that the retention policy has negligible effect during normal times, and only plays a role in recessions.

${ }^{9}$ The reason for the restriction is that extended benefits in recessions come from federal funding, whereas the first 26 weeks of benefits are funded through states. Under the UI regulation prior to July 2010, benefits funded by states must be collected first before federal benefits, and in cases where more than one benefit segments are open, statefunded benefits take precedence. The regulation P.L. 111-205 "Unemployment Compensation Extension Act of 2010", approved on July 22, 2010 (HR 4213), relaxed the funding restrictions and effectively gave the unemployed workers the choice between new and old uncollected benefits (Department of Labor 2015).
} 
earn over a one-year period a multiple (from 3 to 10) of the benefit amount to re-qualify for a new UI segment. The restriction on retention policy before July 2010 means that when an unemployed worker re-qualifies for a new UI segment, she has to start collecting the new segment. Given this restriction, it is easier for an unemployed worker to collect leftover benefits in states with a higher multiple and hence harder to re-qualify. Appendix A contains an example to illustrate the cross-state policy difference. In the empirical section, I exploit the cross-state pattern to demonstrate the effects of retention policy.

Evidence of policy effects on individual choice Are the unemployed workers sufficiently knowledgeable and rational to take into account such complicated policy structures and anticipate changes during future unemployment spells. On the unemployment forum of the web site City-Data, ${ }^{10}$ a popular forum site for U.S. city information with around 1.5 million members, many unemployed workers discussed how taking a temp or part-time job would impact their UI benefit receipts. Figure 1 presents two examples of questions asked on the forum that are related to the retention policy. These two posts illustrate that the unemployed workers do indeed consider the effect of taking a job, especially a temp or part-time job, on their future unemployment benefits.

Figure 1: Example discussions on the retention policy and short-term job on City-Data.

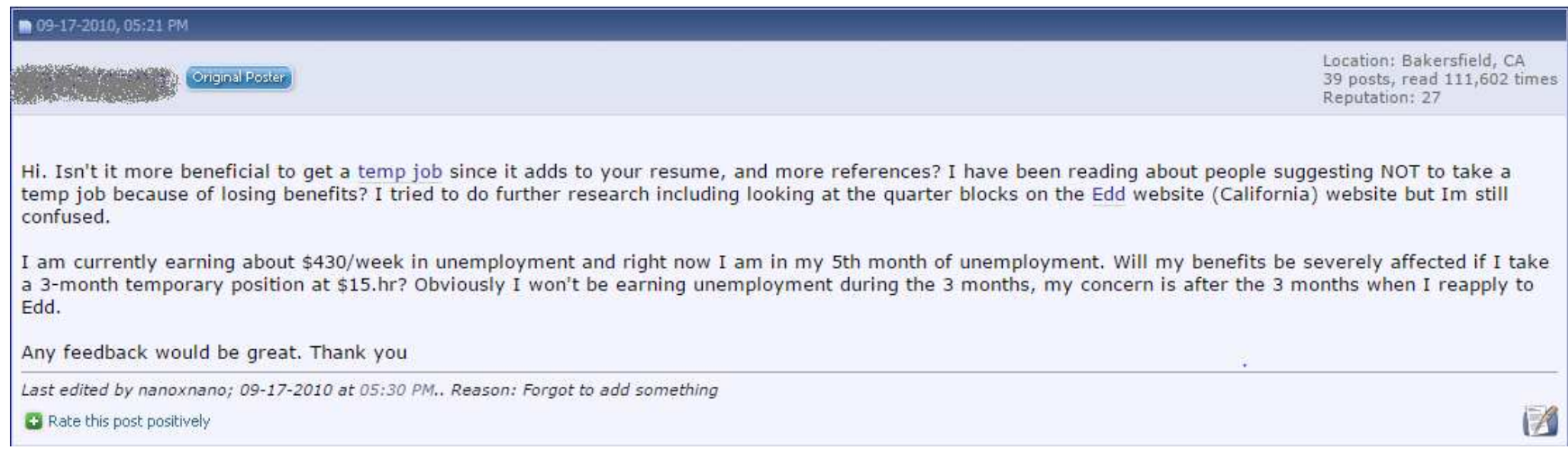

07-27-2013, 01:14 PM
My cousin is in CA and she is about to begin her Tier 2 . With no such luck finding full time employment after 10 months of searching, she decided to accept a
temp job that MAY last $3-6$ months. Or it may last a few days if they don't like her. Was it a wise decision for her to forgo the rest of her Unemployment
Benefits for a temp job? Should she ride out the rest of her benefits and keep applying for full time job instead?
Rate this post positively

\footnotetext{
${ }^{10}$ http://www.city-data.com/forum/unemployment.
} 


\subsection{Empirical evidence on the effect of retention policy}

To empirically document the effect of the retention policy on re-employment, I exploit policy variations across states before July 2010 and the lack of variations after July 2010.

I first group states according to how hard it is to re-qualify for a new UI segment. Group I consists of states where it is easy to re-qualify. These states require a worker to earn 3 to 4 times of her current benefit amount within a one-year period in order to re-qualify. Group II consists of states with income multiples of 5 or 6 . Group III includes states with income multiples of 8 or 10 . In this last group of states it is hardest to re-qualify for new benefits and hence easiest to collect leftover benefits from previous segments. ${ }^{11}$ Figure 2 maps the grouping of states. Geographically, Group I (purple colored) are dispersed throughout the country; Group II (yellow colored) are concentrated in the west, southwest and northeast; Group III (green colored) are mostly in the east and central parts of the country.

Figure 2: State's policy multiple for re-qualifying second UI segment

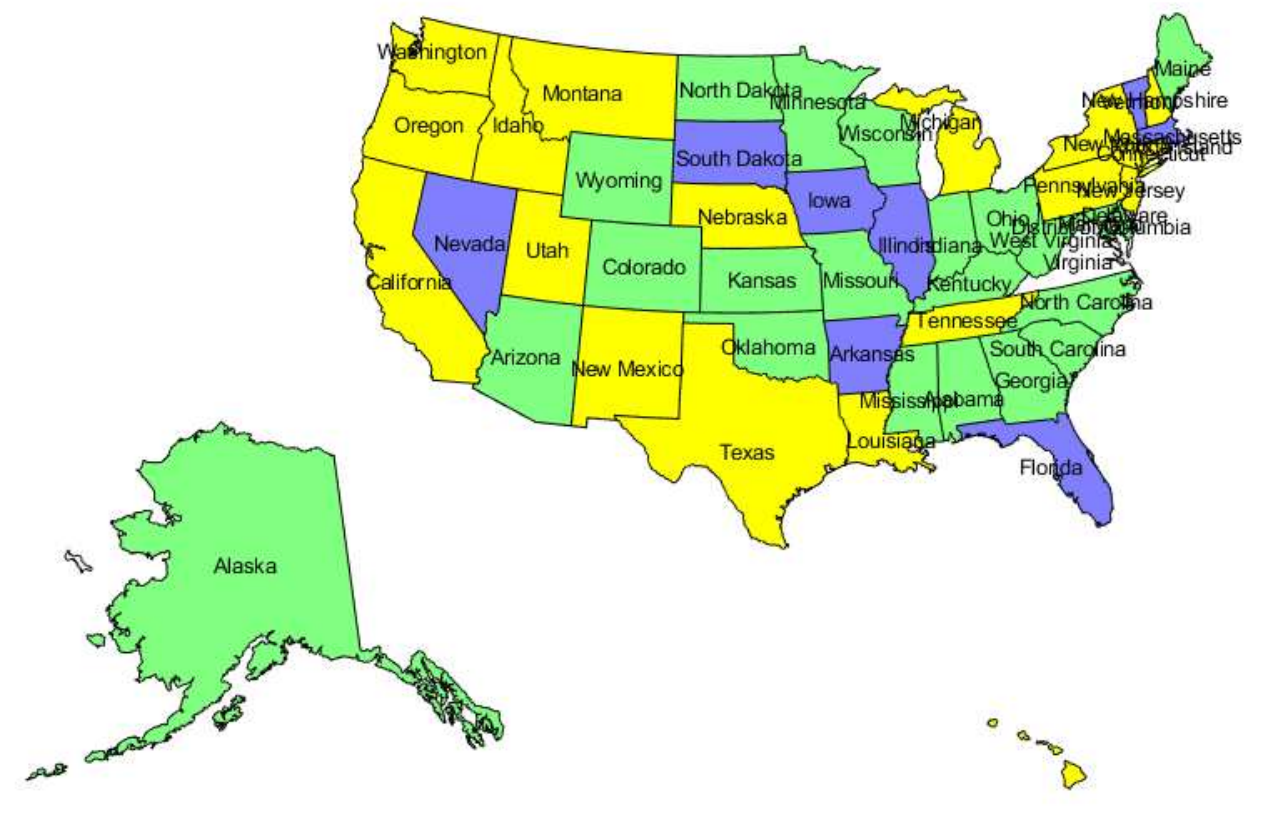

Group I (low multiple) States $\quad$ Group II (medium multiple) States — Group III (high multiple) States

Data come from the Survey of Income and Program Participation (SIPP) to conduct both statelevel and individual-level analyses. The SIPP is a longitudinal survey that interviews respondents every four months and records monthly labor market activities and program (e.g. unemployment

\footnotetext{
${ }^{11}$ No states have a multiple 7 or 9 . Virginia does not have an income requirement to re-qualify for a new segment. In all other states, the re-qualifying threshold (the multiple) remains unchanged during the sample period.
} 
benefit receipt) participation status. The 2008 panel includes information from May 2008 to December 2013, exactly covering the period of UI extensions and the July 2010 federal law.

I restrict the sample to individuals ages 20 to 64 as this is the group most likely to be active participants in the labor market. A person is unemployed if she is without a job and is reportedly actively searching for a new job. Following the literature (e.g. Cullen and Gruber 2000, Chetty 2008, LaLumia 2013), define the start of an unemployment spell as when a person transitions from having a job to having no job. An unemployment spell ends when the person is no longer unemployed. Following the literature, I restrict the sample to workers with some observed work history prior to their first observed unemployment spell. This makes sure the unemployment spell is not left-censored and focuses the sample to individuals with labor force attachment. I use the answers to questions about UI receipt to classify an unemployment spell as "ever/never received UI." In my sample, the reported rates of UI receipt range from $27 \%$ in 2008 to $42 \%$ during 2009-2010.

I use a person's reported state of residence during an unemployment spell to classify her into state groups. ${ }^{12}$ One issue is that the effect of the retention policy potentially depends on the expected duration of benefits and states implemented different UI extensions in the past recession. I exclude states that did not implement the second tier of extension before November 2009. This restriction drops North Dakota, Nebraska, South Dakota, and Utah out of the sample.

State-level analysis I conduct two analyses using the SIPP sample. First, I show state-level aggregate patterns. Specifically, I compute the proportion of unemployment spells ending in re-employment during a period of time. I use the spells ending by June 2010 for the pre-July 2010 analyses and spells ending during Nov 2010-2013 for the post-July 2010 results to allow delays for policy implementation. Table 1 presents the average re-employment measure for each state group and by UI recipient status. Numbers in parentheses indicate the total number of unemployment spells in the sub-group. ${ }^{13}$

Consistent with the intuition, the upper panel of Table 1 shows that among unemployment spells ever receiving UI benefits, the aggregate re-employment measure is higher in states where it is easier to collect previous benefits. For example, in states with the most lenient re-qualifying policy and hence most difficult to collect previous benefits (Group I), $53 \%$ of unemployment spells end in reemployment by June 2010, whereas $59 \%$ end in re-employment in states where it is easiest to collect previous benefits (Group III). The other unemployment spells either end with the individual going out of labor force, or continue by June 2010.

Among the control group of unemployment spells that were never on UI, the re-employment probability does not differ consistently across state groups. The non-recipient group controls for conditions that differ consistently across state groups (for example, firm-side conditions, aggregate

\footnotetext{
${ }^{12}$ Sometimes an unemployed person may move across states (ninety unemployment spells in my sample include at least one move that lead to a change in state group). In cases where such a move changes the state group, I use the person's last state of residence during the spell, assuming she is collecting in her last state residence and so this state's UI policy potentially affects her re-employment incentive and opportunity.

${ }^{13}$ Appendix B includes the re-employment measures for each year. The patterns are consistent with evidence presented here.
} 
Table 1: Cross-State Difference in Re-employment Measure.

\begin{tabular}{clcc}
\hline \hline & $\begin{array}{c}\text { Group I } \\
(8 \text { states })\end{array}$ & $\begin{array}{c}\text { Group II } \\
(16 \text { states })\end{array}$ & $\begin{array}{c}\text { Group III } \\
(22 \text { states })\end{array}$ \\
\hline Spells ever received UI & \multicolumn{2}{c}{ Pre-July 2010: Easier to collect previous benefits } \\
Number of spells & 0.530 & 0.549 & 0.587 \\
Spells never received UI & $(417)$ & $(1164)$ & $(898)$ \\
Number of spells & 0.514 & 0.518 & $(1588)$ \\
\hline Spells ever received UI & $(660)$ & $(1849)$ & 0.491 \\
Number of spells & Post-July 2010: No cross-state difference in retention policy \\
\hline
\end{tabular}

Note: SIPP 2008 panel, restricted to individuals ages 20 to 64 at time of survey. Measure calculates proportion of unemployment spells ending in re-employment. Numbers in parentheses are total number of unemployment for the sub-group. The upper panel uses unemployment spells that end by June 2010, the second lower panel includes spells which end during Nov 2010-2013. Sample restricted to states implementing similar benefit extension tiers: states with no EUC 2 before Nov 2009 ND, NE, SD, UT) are excluded; state with no retention policy (VA) is excluded.

shocks). As a second control group, I look at the UI-receiving spells after July 2010, when a federal law removed the cross-state policy difference on delayed benefit collection. The lower panel of Table 1 shows that in this group, again, there is no consistent pattern across state groups. To the extent that the two control groups capture any economic conditions that vary systematically across state groups, the results here suggest that prior to July 2010 the retention policy, by allowing unemployed workers to collect previous benefits (or equivalently, delay collection of benefits), increases workers' re-employment incentives in a recession.

Individual-level analysis While the state-level patterns are perhaps more transparent, they do not control for individual-level characteristics that may vary consistently across states or state groups. It is also difficult to interpret the economic and statistical significance of the cross-state group differences.

As a second analysis using the SIPP data I use information at the individual level to estimate the hazard of exiting an unemployment spell into a new job. I do so by estimating Cox proportional hazard models, regressing the log hazard rate on a set of dummy variables for state group. ${ }^{14}$ To control for different labor force composition across states, I include controls for individual demographics

\footnotetext{
${ }^{14}$ The setup of the regression model is similar to LaLumia (2013) with the estimating equation:

$$
\log \left(h_{i, t}\right)=\beta \text { StateGroup } i+\gamma X_{i, t}+\epsilon_{i, t}
$$

where $h$ is the hazard rate, StateGroup is a collection of dummy variables for each state group, and $X$ includes all individual and state-level controls and fixed effects. Compared with that paper, I exclude control variables meant to capture the liquidity need and access of the unemployed worker, e.g. number of children, net liquid wealth. For the purpose of my analysis, I also count short employment episodes $(<4$ weeks) as re-employment.
} 
(gender, education, age) as well as pre-unemployment work characteristics (job tenure, monthly earnings, industry). ${ }^{15}$ Additionally, I control for the monthly state-level unemployment rates and include year fixed effects to address issues related to different and time-varying state economic conditions.

Estimates from the hazard model are shown in Table 2. Similar to the state-level analysis, I estimate the model using three samples: (1) UI recipients during 2008-June 2010 (the pre-July 2010 sample); (2) non-UI recipients during 2008-June 2010; (3) UI recipients during Nov 2010-2013 (the post-July 2010 sample). For easy interpretation I report the coefficients (not hazard rates) in this table.

Table 2: Individual-Level Hazard Model Estimates.

\begin{tabular}{lccc}
\hline \hline & $(1)$ Pre-July & $(2)$ Pre-July & (3) Post-July \\
& 2010, UI & 2010, no UI & 2010, UI \\
\hline StateGroup (group II is omitted) & & & \\
I (hardest) & $-0.129^{*}$ & -0.058 & 0.056 \\
III (easiest) & $0.114^{* *}$ & -0.026 & 0.003 \\
White & $0.345^{* *}$ & $0.2325^{* *}$ & 0.103 \\
Married & 0.073 & $0.088^{*}$ & -0.030 \\
High school or less & $-0.312^{* *}$ & -0.024 & -0.0017 \\
Age & 0.026 & 0.018 & $0.043^{* *}$ \\
Age squared & $-0.00046^{* *}$ & $-0.00037^{* *}$ & $-0.00064^{* *}$ \\
Pre-unemp monthly earnings $(\$ 1000)$ & $0.033^{* *}$ & 0.020 & $0.031^{* *}$ \\
Pre-unemp job tenure & $-0.012^{*}$ & $0.014^{* *}$ & -0.001 \\
$\quad$ Left-censored job tenure & -0.120 & 0.042 & $-0.235^{* *}$ \\
State unemp rate & $-0.051^{* *}$ & $-0.057^{* *}$ & $-0.059^{* *}$ \\
Year fixed effects & Yes & Yes & Yes \\
Pre-unemp industry fixed effects & Yes & Yes & Yes \\
Number of spells & 3321 & 4536 & 1989 \\
\hline
\end{tabular}

Note: Table reports coefficients from hazard model estimates. SIPP 2008 panel, restricted to individuals ages 20 to 64 at time of survey. Columns (1)-(2) use samples by June-2010, Column (3) use samples during Nov 2010-2013. Sample restricted to states implementing similar benefit extension tiers: states with no EUC 2 before Nov 2009 ND, NE, SD, UT) are excluded; state with no retention policy (VA) is excluded. ${ }^{* *} p<5 \% .{ }^{*} p<10 \%$.

The key variables of interest are the StateGroup dummies. I omit group 2, so the StateGroup coefficients are relative to group 2. Consistent with the state-level evidence, column (1) shows that before the implementation of federal law in July 2010, the re-employment hazard rate among the

\footnotetext{
${ }^{15}$ Some pre-unemployment job spells are left-censored, which may downward bias the measure of job tenure. I include a dummy variable for when an employment spell is left-censored. To control for the pre-unemployment industry I include broad categories of industry fixed effects. The industries are: construction, manufacturing, wholesale, retail, transportation, administration, education, health care, accommodation and food, other services, and other industries. They are meant to capture the industry-specific skills acquired at these pre-unemployment jobs, which may affect the worker's ability and incentive to get re-employed in a different industry.
} 
UI recipients in group I states (hardest to collect previous benefits) is about 13 percent lower than the re-employment hazard of UI recipients in group II states (significant at the 10\% level); and the re-employment rate in group III states (easiest to collect previous benefits) is 11 percent higher than that in group II states (significant at the $5 \%$ level). The StateGroup coefficients in columns (2) and (3) do not show similar patterns: both groups I and III have lower re-employment rates than group II states among non-UI recipients; both groups I and III have higher re-employment rates than group II among UI recipients after the implementation of the federal law; and none of these coefficients are statistically significant even at the $20 \%$ level. ${ }^{16}$

The empirical analyses so far suggest that the retention policy may indeed have an impact on the work decision of unemployed workers. In the next two sections I use a structural model that incorporates the necessary policy elements to illustrate how the retention policy affects individual behavior, and use model counterfactuals to evaluate the aggregate effects.

\section{A Baseline Model}

This Section extends the canonical McCall (1970) framework to include UI eligibility and wage indexed benefits and then illustrates the effect of the U.S. retention policy on the job-finding incentives of workers. As the retention policy has small effects when UI benefits are relatively short-lived, such as during non-recessionary times, I assume that the economy is in a recession and has sufficiently extended UI payments. ${ }^{17}$ To ease exposition, I initially assume that eligibility and exhaustion of benefits follow probabilistic processes. The quantitative exercise in the next section adopts processes that more closely follow the institutional details.

\subsection{Model setup}

Environment Time is discrete and infinite. The economy consists of a mass of infinitely lived workers. The measure of workers is normalized to one. In any given period, a worker can be either employed or unemployed. I assume risk-neutral workers for now, and consider risk-averse workers in

\footnotetext{
${ }^{16}$ Perhaps reassuringly, some of the control variables have similar effects across the three samples: being white, having higher pre-unemployment monthly earnings are associated with higher re-employment probabilities, while living in states with higher unemployment rates and being less educated (only significant for the first sample) are associated with lower re-employment probabilities. One thing worth noting is the positive correlation between pre-unemployment earning and re-employment rates. This does not detract from the story here. Individuals who make more at their pre-unemployment jobs may be better positioned to find a new job (e.g. better networks, a wide range of jobs to choose from). The mechanism emphasized in present paper is how the expectation of low-paying jobs leading to low benefits in future unemployment deter individuals with relatively high prior earnings from taking these jobs.

${ }^{17}$ For the analysis in this section, I assume the recession is long enough to reach a near steady state.
} 
the quantitative exercise. Workers maximize expected lifetime utility given by

$$
\mathbb{E}_{0} \sum_{t=0}^{\infty} \beta^{t} c_{t}
$$

where $\mathbb{E}_{0}$ is the period 0 expectation factor, and $\beta$ is the time discount factor. Period utility comprises of utility from consumption of goods $c$ and is increasing in $c$. Each period, an employed worker gets paid wages $w$, which depend on the type of the job. An unemployed worker receives $\underline{c}$ from non-monetary benefits such as leisure and home production. Additionally, if the unemployed worker qualifies for unemployment benefits, she also receives $b$ which is a function of previous wages. There are no private insurance markets and workers cannot save or borrow.

Labor market With probability $\rho$ each period an unemployed worker receives a job offer. A proportion $\rho_{g}$ of the jobs are 'good' jobs with higher wages and longer expected job tenure; and the rest $\rho_{b}=1-\rho_{g}$ are 'bad' jobs. ${ }^{18}$ Depending on the job type, with an exogenous job separation probability $\delta_{g}$ or $\delta_{b}$ each period, a worker becomes unemployed. Good and bad jobs differ in the following ways: Good jobs pay higher wages and have longer expected job tenure than bad jobs, $w_{g}>w_{b}$ and $\delta_{g}<\delta_{b}$, but good jobs are scarcer $\rho_{g}<\rho_{b}$.

UI policy structure Not all unemployed workers receive benefits. With probability $\lambda$ a newly unemployed worker qualifies for new benefits. Each period, benefits expire with an exogenous probability $e$, so that benefits do not last forever. In the quantitative model, I model benefit exhaustion discretely. UI benefits are indexed on wages of previous employment through $\gamma \omega$, where $\gamma$ has the interpretation of the monetary replacement ratio, and $\omega$ denotes wages at the previous job.

Worker's problem An unemployed worker has individual state $\omega$, which equals the wages at her previous employment $\left\{w_{g}, w_{b}\right\}$ if she has benefits, or 0 if no benefits. When a bad job offer arrives (with probability $\rho \rho_{b}$ ), the unemployed worker chooses whether to accept it or wait for a better job offer. Her problem can be written recursively as follows for $\omega \in\left\{w_{g}, w_{b}, 0\right\}$,

$$
\begin{aligned}
U(\omega)= & \gamma \omega+\underline{c}+\beta \underbrace{(1-\rho)[e U(0)+(1-e) U(\omega)]}_{\text {doesn't receive a job offer }} \\
& +\beta \underbrace{\beta \rho \rho_{g} W_{g}(\omega)+\rho_{b} \overbrace{\max \left\{W_{b}(\omega), e U(0)+(1-e) U(\omega)\right\}}^{\text {accept } / \text { reject bad job }}]}_{\text {receives a job offer }},
\end{aligned}
$$

where $U$ is the unemployed worker's value function, and $W_{k}$ is the value function of a worker employed

\footnotetext{
${ }^{18}$ This specification avoids the cases of having two (one good and one bad) jobs. It assumes that workers send out multiple job requests or resumes each period, and that the marginal cost of sending a job application is low such that workers send resumes to job postings that ex post he would not take.
} 
at job type $k=\{g, b\}$ and is given by

$$
W_{k}(\omega)=w_{k}+\beta \underbrace{\left(1-\delta_{k}\right) W_{k}(\omega)}_{\text {keeps job }}+\beta \underbrace{\delta_{k}\left[\lambda U\left(w_{k}\right)+(1-\lambda) U(\omega)\right]}_{\text {loses job }} .
$$

In the above unemployed worker's problem, her current consumption consists of base consumption $\underline{c}$ and benefits $\gamma \omega$ (if no benefits then $\omega=0$ ). If she doesn't receive a job offer, then with probability $e$ she loses benefits next period. With probability $\rho$ she receives a job offer. Conditional on receiving an offer, the job is a good job $(g)$ with probability $\rho_{g}$. Without loss of generality, I assume for now that a good job is good enough that an unemployed worker does not reject it. If the job offer is a bad job $(b)$, the unemployed worker decides whether to accept it and start working the next period, or reject it and wait for a better future offer. The cost of waiting is lower consumption in unemployment relative to employment, and the possibility of benefit exhaustion next period (with probability $e$ ).

A worker at job type $k$ gets paid wages $w_{k}$. With the type specific job separation probability $\delta_{k}$ she loses her job and becomes unemployed next period. With probability $\lambda$ the newly unemployed worker qualifies for new benefits $\gamma w_{k}$ next period, otherwise she can collect any leftover benefits from when she was last unemployed at the benefit level $\gamma \omega$, where again $\omega \in\left\{w_{g}, w_{b}, 0\right\}$. This last part captures the retention policy. Without it, a newly unemployed worker who does not qualify for new benefits will go without benefits.

It is important that an employed worker inherits the individual state $\omega$ from when she was last unemployed. This keeps track of her previous benefit status and level, and the difference between past and current benefits is important to the retention policy. In particular, $\omega=0$ means she did not have benefits (or benefits ran out) by the end of her previous unemployment spell, and so when she becomes unemployed again she either gets new benefits if her current job qualifies for new benefits or no benefits.

\subsection{Retention policy and job take-up}

From the unemployed worker's problem, an unemployed worker with benefits $\gamma \omega$ accepts a bad job if and only if

$$
W_{b}(\omega) \geq e U(0)+(1-e) U(\omega)
$$

Assuming unemployed workers without benefits do not reject jobs, i.e. $W_{b}(0) \geq U(0)$, so

$$
U(0)=\underline{c}+\beta(1-\rho) U(0)+\beta \rho\left[\rho_{g} W_{g}(0)+\rho_{b} W_{b}(0)\right]
$$


Writing (4) explicitly for $\omega \in\left\{w_{g}, w_{b}\right\}$, she accepts the job if and only if

$$
\begin{aligned}
0 \leq \quad & w_{b}-\underline{c}-(1-e) \gamma \omega+\beta\left(1-\delta_{b}-\rho\right)\left[W_{b}(\omega)-(e U(0)+(1-e) U(\omega))\right] \\
& +\underbrace{\beta \rho e\left[\rho_{g}\left(W_{g}(\omega)-W_{g}(0)\right)+\rho_{b}\left(W_{b}(\omega)-W_{b}(0)\right)\right]-\beta \rho \rho_{g}\left[W_{g}(\omega)-W_{b}(\omega)\right]}_{\text {job type effect }} \\
& +\underbrace{\beta e\left(1+\delta_{b}-e-\rho+\rho e\right)[U(\omega)-U(0)]}_{\text {benefit eligibility effect }}+\underbrace{\beta \lambda \delta_{b}\left[U\left(w_{b}\right)-U(\omega)\right]}_{\text {retention effect }} .
\end{aligned}
$$

The first line contains the standard incentives to accept a job: Accept if the wage from a bad job $\left(w_{b}\right)$ is high enough relative to the combined base consumption $(\underline{c})$ and benefits $(\rho \omega)$ if any; or if the future value of working at a bad job is high enough relative to the value of unemployment.

There are three additional effects. All three effects take place in the periods after the next period (hence discounted by $\beta$ ). First, the job type effect represents the marginal gain (loss) of accepting a bad job relative to waiting for a good job. In particular, a larger share of good jobs (larger $\rho_{g}$ ) or a larger difference in the values of good and bad jobs reduces the likelihood of accepting a bad job. Second, the benefit eligibility effect represents the additional value of keeping benefits, which disappears when benefits last forever $(e=0)$. Third, the retention effect comes from the difference between the value of being unemployed after taking a bad job $\left(U\left(w_{b}\right)\right)$ and the value of current unemployment $(U(\omega))$.

The retention effect is zero if the current benefit level is low $\left(\omega=w_{b}\right)$, and negative if the current benefit level is high $\left(\omega=w_{g}\right)$. A negative retention effect makes it less likely for a worker to accept a bad job offer. Due to the retention effect, unemployed workers who had higher wages and hence high benefits are more likely to reject bad job offers. When bad jobs are less secure ( $\delta_{b}$ is larger), the negative effect of retention policy is amplified. ${ }^{19}$ The size of the effect is also larger when it is easier to qualify for new benefits ( $\lambda$ is larger), or with a larger wage gap $w_{g}-w_{b}$. Additionally, the effect of the retention policy should also depend on how long the unemployed worker can collect benefits, because the longer she can collect, the more benefits she can potentially carry over to future unemployment spells. But because all unemployed workers face the same benefit exhaustion probability $e$, this effect is not present in the simple model. For the quantitative model in the next section, I model discrete benefit exhaustion, and so workers at different point in their unemployment spell face different benefit exhaustion probabilities ( 0 or 1 ).

The retention effect here assumes workers do not have the choice between old and new benefits. More specifically, the unemployed worker receiving high benefits today is discouraged from accepting low-paying jobs because of the prospect of lower benefits in future unemployment spells. The

\footnotetext{
${ }^{19} \mathrm{~A}$ larger $\delta_{b}$ also reduces the value of unemployment with low benefits, and increases the size of the unemployment value difference $\left|U\left(w_{b}\right)-U\left(w_{g}\right)\right|$, which further increases the effect of the retention policy. This relationship is confirmed in the quantitative model.
} 
parameter $\lambda$ here captures the cross-state difference in policy explained in the previous section. A larger $\lambda$ corresponds to states where it is easier to re-qualify for new benefits after a short period of employment. Because when a newly unemployed worker qualifies for new benefits she has to forfeit her old uncollected benefits, the negative incentives on job take-up by high-benefit unemployed workers are also more severe in these states.

After July 2010. Consider the policy after July 2010, when a federal law removed the cross-state differences in the retention policy by giving workers a choice between new and old benefits. Now the retention effect becomes

$$
\beta \lambda \delta_{b} \max \left\{U\left(w_{b}\right)-U(\omega), 0\right\}=0
$$

In this case, because the unemployed worker can choose between the leftover benefits $(\gamma \omega)$ and new benefits, the retention effect is zero. The retention policy does not have any additional incentive effects on the worker with higher benefits $\left(\omega=w_{g}\right)$.

\section{Quantitative Analysis}

This section quantifies the effect of the retention policy during a recession. The empirical evidence presented in Section 2 provides some directions for modeling choice. A structural model allows for counterfactual analyses to isolate the effects of policy from cyclical changes in the labor market.

It extends the illustrative simple model in the previous section to introduce risk-averse workers, duration-dependent UI benefit exhaustion and re-qualification. With risk aversion workers have incentives to self-insure through job choices. Non-stochastic UI exhaustion means an unemployed worker collecting her first week of benefits will make different job decisions from someone at her last week of benefits. This difference is both consistent with empirical findings and relevant for the choice between new and old benefits. As extensions to the baseline quantitative model, I further allow workers to save and borrow and consider alternate assumptions on the UI system and the labor market in the next section.

\subsection{Quantitative model}

The quantitative model retains many features from the previous section. The first notable change is that workers are risk averse with utility from consumption at time $t$ given by $u\left(c_{t}\right)$.

Below I highlight the other key differences.

UI policy Newly unemployed workers may qualify for entitlement of benefits for a length of $J_{t}$ periods. When an unemployed worker exhausts her entitlement, she becomes unemployed without benefits and consumes base consumption. In other words, there is no stacking of multiple segments of benefits. As with the previous section, benefit levels are proportional to wages of the most recent 
employment spell.

Two remarks are in order. First, in the U.S. unemployment benefits are often not linear in past wages, but are bounded at the top. Incorporating this feature would reduce the difference in the values of unemployment with low and high benefits when the high benefit hits the upper bound $\left(U\left(w_{b}\right)-W\left(w_{g}\right)\right.$ of the retention effect in Equation (6)). Consequently, the effect of the retention effect is smaller. Second, in most U.S. states (all but nine states), not everyone qualifies for the maximum entitlement. Instead, workers who have not earned sufficient wages or worked long enough within the past year qualify for shorter benefit entitlements. This feature makes taking a temp job even less appealing, and potentially increases the impact of the retention policy. I discuss the relevance of these features for the quantitative results in Section 5.

Unlike in the previous section, here I model the retention policy by keeping track of discrete periods of employment on temp jobs. Workers re-qualify for new benefits when they have accumulated enough wage earnings by the state's standard. ${ }^{20}$ For workers on regular jobs I use a Poisson process to model benefit qualification, for two reasons. First, the re-qualify rule applies to earnings accumulated within a short period of time, typically one year, and workers on regular jobs with much longer expected job tenures are not subject to the re-qualify rule. Second, workers sometimes do not collect benefits that they qualify, for reasons outside the scope of this paper. Non-collection is likely more prevalent among workers on regular jobs. As such, using a discrete process to model benefit eligibility for regular job workers would overstate the population of UI recipients. ${ }^{21}$

Labor market Similar to the previous section, there are two types of jobs, regular job and temp job. Regular jobs pay higher wages than temp jobs. In particular, wages of regular jobs are drawn from a known distribution, whereas the wages of temp jobs are fixed at a lower bound $\underline{w}$. The different wage structures mirror reality: temp jobs often have fixed wages around the minimum wage level, whereas regular jobs offer a menu of wages. Section 5 introduces multiple wages for temp jobs as well.

Additionally, regular jobs have longer expected job tenures, i.e. lower exogenous job separation rates $\delta_{g, t}<\delta_{b, t}$. In a recession, regular jobs become less secure, i.e. $\delta_{g, t}$ becomes larger, whereas the expected job tenure of temp jobs remains unchanged over the cycle. This assumption is motivated by the observation that while the probability of being laid off from a regular job is likely higher during recessions, the probability of ending a temp job is mostly unchanged throughout cycles. Job arrival rates are summarized by $\rho_{t}$ and $\rho_{g, t}$, similar to the simple model. In a recession, both $\rho_{t}$ and $\rho_{g, t}$ become smaller. Not only do jobs become scarcer overall but good jobs become even more so than bad jobs. ${ }^{22}$

\footnotetext{
${ }^{20}$ This also means workers may have an incentive to quit before they qualify for new benefits, if they would rather collect old benefits. I do not allow quitting in the benchmark model here, and explore the alternative in Section 5 .

${ }^{21}$ For discussions on non-collection see, for example, Auray, Fuller, and Lkhagvasuren (2019).

${ }^{22}$ In the calibration, both $\rho \rho_{g}$ and $\rho \rho_{b}$ are smaller in the recession. In other words, the unconditional arrival rates of both type jobs become lower in a recession.
} 
Worker's problem In addition to the previous wages $\omega$ of an unemployed worker, I also keep track of her UI usage with the individual state $j$, which records the number of periods of the current UI spell that she has used. While $\omega$ does not change throughout an unemployment spell, $j$ increases by 1 each period during the same unemployment spell, until it reaches the maximum potential entitlement $J_{t}$. $J_{t}$ may be time-varying: larger in recessions than during normal times because of benefit extensions. This is consistent with the implementation of benefit extensions in the U.S. A worker originally entitled for 26 weeks at the time of her job separation may end up receiving 52 weeks as a result of extensions. $^{23}$ Once all benefit entitlement are exhausted, she becomes unemployed without benefits $(\omega=0, j=0)$. Each period, the unemployed worker receives a job offer, either a regular job or a temp job, according to the stochastic processes outlined before. She then decides whether to accept the job. ${ }^{24}$

The unemployed worker's problem can be written as

$$
\begin{aligned}
U_{t}(\omega, j)= & u(\gamma \omega+\underline{c})+\beta\left(1-\rho_{t}\right) V_{t+1}(\omega, j) \\
& +\beta \rho_{t}\left[\rho_{g, t} \mathbb{E}_{\mathbf{w}} \max \left\{W_{g, t+1}(\mathbf{w}), V_{t+1}(\omega, j)\right\}+\rho_{b, t} \max \left\{W_{b, t+1}(\omega, j, 1), V_{t+1}(\omega, j)\right\}\right](8)
\end{aligned}
$$

where

$$
V_{t+1}(\omega, j)=\mathbb{1}\left\{j=J_{t}\right\} U_{t}(0,0)+\mathbb{1}\left\{j<J_{t}\right\} U_{t}(\omega, j+1)
$$

is the value of entering period $t+1$ without a job. I use $J_{o b_{g, t}}(\omega, j, \mathbf{w}), \quad J o b_{b, t}(\omega, j) \in\{0,1\}$ to denote the time- $t$ decisions to reject/accept a regular job (at wage $\mathbf{w}$ ) and a temp job, respectively. I focus on these job take-up decisions later to demonstrate the impacts of policy on individual choices. Because of the restriction of at most one job offer in each period, an unemployed worker with a job offer will only make one reject/accept decision.

Workers on regular jobs are not subject to the income requirement of the re-qualify rules and are not affected by the retention policy. Their only individual state is the wage, which is initially drawn from a known distribution $F(\mathbf{w})$, with support $\mathbf{w} \in\left[w_{L}, w_{H}\right]$, and remains unchanged during the same employment spell. A worker newly unemployed from a regular job collects benefits with

\footnotetext{
${ }^{23}$ This setup may become problematic if the original entitlement is longer than the subsequent maximum entitlement, e.g. $J_{t-1}>J_{t}$. This happens when UI benefit extensions are (gradually) removed. In reality, the worker can potentially collect all $J_{t-1}$ periods of benefits even though the current maximum benefit period is lower than her entitlement. The setup here does not take this into account. But since the transitional period I analyze (up until 2012) only had extensions and no removals, this issue does not create a problem here.

${ }^{24}$ For simplicity I make the restriction that an unemployed worker receives at most one job offer in each period. In other words, with probability $\rho_{t}$ the unemployed gets a chance to draw a job. Proportion $\rho_{g, t}$ of all job offers are regular jobs, and by law of large numbers that is the probability that the worker 'draws' a regular job offer.
} 
probability $\lambda$. Her value function is given by

$$
W_{g, t}(\mathbf{w})=u(\mathbf{w})+\beta\left(1-\delta_{g, t}\right) W_{g, t+1}(\mathbf{w})+\beta \delta_{g, t}\left[\lambda U_{t+1}(\mathbf{w}, 1)+(1-\lambda) U_{t+1}(0,0)\right]
$$

Workers on temp jobs are subject to the income requirement of the re-qualify rule and the retention policy, and they have the choice between new and old UI after July 2010. So the worker's individual states include the same states inherited from her previous unemployment: $(\omega, j)$, which stay unchanged during the temp job. An additional state $j w$ keeps track of the number of periods employed and increases each period during the same spell. To simplify the analysis, no quitting is allowed in this baseline model. The temp worker's value function is given by ${ }^{25}$

$$
\begin{aligned}
& W_{b, t}(\omega, j, j w)=u(\underline{w})+\beta\left(1-\delta_{b, t}\right) W_{b, t+1}(\omega, j, j w+1) \\
& +\left\{\begin{array}{l}
\text { (recession, before July 2010) } \\
\beta \delta_{b, t}\left[Q_{s}(\omega, j w) U_{t+1}(\underline{w}, 1)+\left(1-Q_{s}(\omega, j w)\right) U_{t+1}(\omega, j)\right] \\
(\text { recession, after July 2010) } \\
\beta \delta_{b, t}\left[Q_{s}(\omega, j w) \max \left\{U_{t+1}(\underline{w}, 1), U_{t+1}(\omega, j)\right\}+\left(1-Q_{s}(\omega, j w)\right) U_{t+1}(\omega, j)\right] \\
(\text { non-recession) } \\
\beta \delta_{b, t}\left[Q_{s}(\omega, j w) U_{t+1}(\underline{w}, 1)+\left(1-Q_{s}(\omega, j w)\right) U_{t+1}(0,0)\right]
\end{array}\right.
\end{aligned}
$$

where

$$
Q_{s}(\omega, j w)=\mathbb{1}\left\{\underline{w} \times j w \geq X_{s} \gamma \omega\right\}
$$

is an indicator whether the worker has worked enough to re-qualify for a new UI segment. It depends on the income requirement multiple $X_{s}$ which differs across U.S. states, the worker's previous benefit level $\gamma \omega$, and the cumulative wages earned during the current employment spell $\underline{w} \times j w$.

In a recession, when the retention policy has the most impact, a newly unemployed temp worker who does not re-qualify for new benefits can use any leftover benefits from her previous unemployment spell. New and old benefit segments potentially differ in both benefit level and duration: new benefit level is linked to the wage of the temp job $\underline{w}$ and has the full duration entitlement $J_{t}$; old benefit level depends on her previous wages $\omega$ and the benefit duration is the number of uncollected periods from previous unemployment spell. Before July 2010, if an unemployed worker re-qualifies for new benefits, she has to start the new UI segment; after July 2010, she can choose whether to start the

\footnotetext{
${ }^{25}$ Because the re-qualify criterion (modeled by $Q_{s}$ here) depends on previous benefit level $\omega$, the workers who do not have benefits in the previous unemployment spell $(\omega=0)$ are not subject to the retention policy. I modeled them as facing the UI collection probability $\lambda$ when they become unemployed.
} 
new UI segment or continue collecting the leftover benefits. ${ }^{26}$ I use $F i x_{t}(\omega, j) \in\{0,1\}$ to denote the choice between old/new benefit segment in the post-July 2010 policy regime. During normal times, the retention policy does not apply, and thus if a newly unemployed worker does not re-qualify for new benefits, she becomes unemployed without benefits.

Stationary economy Given a UI policy regime, the economic conditions (job separation and arrival rates) and the distribution of wages, a stationary economy is a collection of value functions, decision rules and worker's distribution, such that workers optimize by solving the problem stated above, and the distribution of workers over individual states is stationary.

I compare the different policy regimes both in a steady state stationary economy resembling the 2012 economy, and over a transition path during 2008-2012. ${ }^{27}$ The initial steady state on the transition path is the pre-recession economy during 2005-2007, and the final steady state is the economy in 2012. First I describe the calibration of parameters in the steady states.

\subsection{Parametrization}

I calibrate for the 2005-2007 economy using the steady state without UI extensions, and for the 2012 economy using the steady state with UI extensions, the retention policy and the federal law. Some parameters are time-invariant such as preference parameters, and others are time-dependent, especially labor market parameters. Table 3 summarizes the values of parameters. The model period is one week.

The utility of consumption takes the following functional form

$$
u(c)=\frac{c^{1-\sigma}}{1-\sigma} .
$$

I pick two parameters related to preferences. The discount factor $\beta$ is set to give a quarterly discount factor of 0.99. The coefficient of relative risk aversion $\sigma$ is set to 2. The UI replacement ratio $(\gamma)$, the ratio of benefits to wages, is set at 0.4 based on the numbers reported on the U.S. Department of Labor (DOL) website for post-2000.

The temp job wage $(\underline{w})$ is set at 0.35 (normalized). The separation rate from temp jobs is calibrated to an average expected job tenure of about one quarter $\left(\delta_{b}=0.08 \approx 1 / 13\right)$. Both the

\footnotetext{
${ }^{26}$ As an example, suppose a worker becomes employed at a temp job after collecting 20 out of 26 weeks of UI benefits at $\$ 20$ per week. She subsequently does not re-qualified for a new UI segment when she loses her temp job. In this case she can collect the remaining 6 weeks at $\$ 20$ per week. If she re-qualifies for a new UI segment of 26 weeks at $\$ 10$ per week, then before July 2010, she has to collect the new benefits and forfeit the old segment. Post-July 2010, she has a choice between collecting $\$ 10 /$ week for 26 weeks and $\$ 20$ week for 6 weeks. It becomes clear from this example that workers with longer previous unemployment spell (e.g. 2 weeks left over from the first UI segment) would most likely prefer to collect the new benefits which pay out less each week but last longer; those with shorter previous unemployment spell (e.g. 20 weeks left over) should prefer to collect the old benefits.

${ }^{27}$ I use 2012 as a relative steady state because by 2012 UI extensions have plateaued, the average job separation rates have fallen back to pre-recession levels, and it has also been sometime after the change in federal policy in July 2010.
} 
Table 3: Summary of Parameters at Relative Steady States

\begin{tabular}{|c|c|c|c|}
\hline Parameter & Description & \multicolumn{2}{|c|}{ Values } \\
\hline \multicolumn{4}{|c|}{ Time-invariant parameters } \\
\hline$\beta$ & Time discount factor & \multicolumn{2}{|c|}{$0.99^{1 / 13}$} \\
\hline$\sigma$ & Coefficient of relative risk aversion & \multicolumn{2}{|c|}{2} \\
\hline$\gamma$ & UI replacement ratio & \multicolumn{2}{|c|}{0.4} \\
\hline$\underline{c}$ & Base consumption & \multicolumn{2}{|c|}{0.02} \\
\hline$\lambda$ & Prob. of UI collection from regular job & \multicolumn{2}{|c|}{0.5} \\
\hline$\underline{w}$ & Wages on temp job & \multicolumn{2}{|c|}{0.35} \\
\hline$\delta_{b}$ & Temp job separation rate & \multicolumn{2}{|c|}{0.08} \\
\hline$\left[w_{L}, w_{H}\right]$ & Wages of regular job & \multicolumn{2}{|c|}{$[0.3,0.95]$} \\
\hline$f(\mathbf{w})$ & Distribution of regular job wage offer & \multicolumn{2}{|c|}{ See Figure 3 blue cross } \\
\hline \multicolumn{4}{|c|}{$\underline{\text { Time-varying parameters }}$} \\
\hline & & $2005-2007$ & 2012 \\
\hline$\rho$ & Steady-state job arrival rate & 0.25 & 0.25 \\
\hline$\rho_{g}$ & Steady-state proportion of regular job offer & 0.5 & 0.195 \\
\hline$\delta_{g}$ & Steady-state regular job separation rate & 0.0031 & 0.0031 \\
\hline$J$ & Steady-state UI entitlement & 26 & $26+66$ \\
\hline
\end{tabular}

wages and expected job tenure of temp jobs are time invariant, which means any changes in the temp job accept/reject decision over time is driven by changes in the value of waiting (for a better offer) and the value of unemployment. The value of non-monetary benefits $(\underline{c})$ is set at 0.02 consistent with Shimer (2005)'s low value of non-UI value of unemployment. ${ }^{28}$ The maximum potential UI entitlement is 26 weeks in $2005-2007$ and $26+66$ (extensions) $=92$ weeks in 2012 . The job separation rate from regular jobs is taken from data and at a weekly rate of 0.0031 for both 2005-2007 and 2012 .

I use the SIPP 2004 panel to calibrate the wage distribution of regular jobs in 2005-2007. To separate temp jobs, which typically have lower wages and shorter expected job tenure, from regular jobs in the data, I use the observed job tenure to classify jobs: short-tenure jobs with less than or equal to 4 months of observed tenure, and long-tenure with more than 12 months of observed tenure. Jobs for which the entire tenure is not observed are not counted if the observed tenure is less than 4 months. Using this classification, I find that the median hourly wage of short-tenure jobs is lower than the median wage of long-tenure jobs during 2005 -2007 (\$7.02 versus $\$ 11.36) .{ }^{29}$ I set the bounds

\footnotetext{
${ }^{28}$ Because there is no job search cost in the model, I need a base consumption for the unemployed that is lower than the usual value of home production used in models with intensive job search and associated search cost. As such, this base consumption can be interpreted as the value of home production less the cost of time and money associated with obtaining an offer.

${ }^{29}$ I have also experimented with other ways to separate by job tenure, e.g. less than or equal to $1,2,3$ months for short-tenure; longer than 4, 6, 9 months for long tenure. The different classifications all give higher median wage at long-tenure jobs. Given the weekly job separation rates of temp (0.08) and regular jobs (0.0031), the classification used here seems the most reasonable.
} 
on regular job wages used in the model to $0.3\left(w_{L}\right)$ and $0.95\left(w_{H}\right)$, which correspond to the $10^{t h}$ and $80^{\text {th }}$ percentiles of long-tenure job wages. ${ }^{30}$ In other words, some regular job offers may pay less than the temp jobs, but the former offers better job security. This is meant to capture the left-tail of the wage distribution among longer-tenure jobs. Given the range of the regular job wages, the distribution of regular job offers $f(\mathbf{w})$ is then discretized using 10 bins.

In the initial steady state (2005-2007) I jointly calibrate (1) the steady-state proportion of regular jobs $\rho_{g},(2)$ the job arrival rate $\rho$ and (3) the probability density of regular job wage offers $f(\mathbf{w})$ to match (a) the proportion of earnings changes that are negative, (b) the unemployment rate and (c) the wage distribution of accepted regular jobs during 2005-2007. I hold the wage distribution $f(\mathbf{w})$ unchanged after the initial period, and allow the job arrival rates $\rho$ and $\rho_{g}$ to vary over time, so in 2012 I only calibrate (1)-(2) with targets (a) and (b).

The empirical counterpart of earnings change is calculated based on employment-unemploymentemployment (EUE) spells constructed using the SIPP 2004 and 2008 panels. For re-employment jobs starting during 2005-2007 (2004 panel) around 40\% had negative earnings change compared to pre-unemployment earnings. The proportion is similar for re-employment starting in 2012 (from 2008 panel). I target unemployment rates of $4.2 \%$ during $2005-2007$ and $8.5 \%$ in 2012 . Note that because the distribution of wage offers $f(\mathbf{w})$ is not observed in the data, I use the stationary distribution of accepted job offers to match the observed wage distribution. The wage distribution of accepted regular jobs comes from SIPP and is plotted in Figure 3 (black triangle) along with the model generated distribution (red circle) and the distribution of offered wages $f(\mathbf{w})$ needed to generate the distribution (blue cross). At the lower end of the distribution the density of offers is higher than the density of accepted wages. Many offers at the lower end are turned down as some unemployed workers find it optimal to wait for better job offers, which is especially true during the first few periods of UI collection. As UI benefits run out, unemployed workers start taking these lower-paying jobs as they come.

The distribution of earnings changes is important for the quantitative exercise. As a calibration check, I compare the model-generated distribution of earnings changes to the data from 2005-2007 in Figure 4. The plot shows the earnings changes as ratios of the individual's pre-unemployment wages. I then group the earnings changes in both data and model into bins of size 0.1 for easy comparison, with x-axis marking the centers of the bins. The model (red circle) generates the bell-

\footnotetext{
${ }^{30}$ Specifically, using the SIPP 2004 panel, I look at hourly wages for all jobs starting between 2005-2007. I first classify jobs into short-tenure ( $<=4$ months with full employment spell observed) and long-tenure ( $>12$ months). I find the median hourly wage of short-tenure jobs during this period is $\$ 7.02$, setting this to be the normalized temp job wage. I then use this value to normalize the long-tenure job wages. A normalized value of 0.3 corresponds to $\$ 6.02$ which is the $10^{t h}$ percentile on the long-tenure job wage distribution, and a normalized value of 0.95 is the $80^{t h}$ percentile. As an alternative measure of earnings I use the reported monthly earnings of the jobs. The median monthly earnings is $\$ 1014$ for short-tenured jobs, and $\$ 1861$ for long-tenured jobs; the normalized values of 0.3 and 0.95 correspond to the $15^{\text {th }}$ and $70^{\text {th }}$ percentiles on the long-tenure job monthly earnings distribution. Both hourly wages and monthly earnings are top-coded. The chosen normalized range seems reasonable given that it covers a wide range of earnings on both income measures.
} 
Figure 3: Distribution of regular job wages in the initial steady state

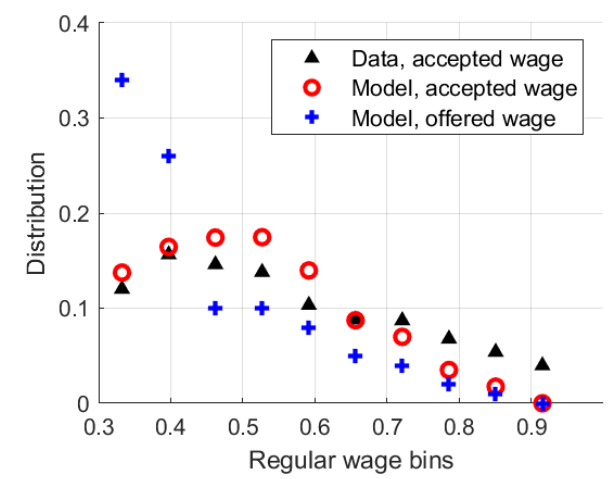

Note: Data of accepted wage density distribution come from SIPP 2004 panel, for all jobs accepted during 2005-2007 lasting more than 12 months.

Figure 4: Distribution of earnings changes in initial steady state

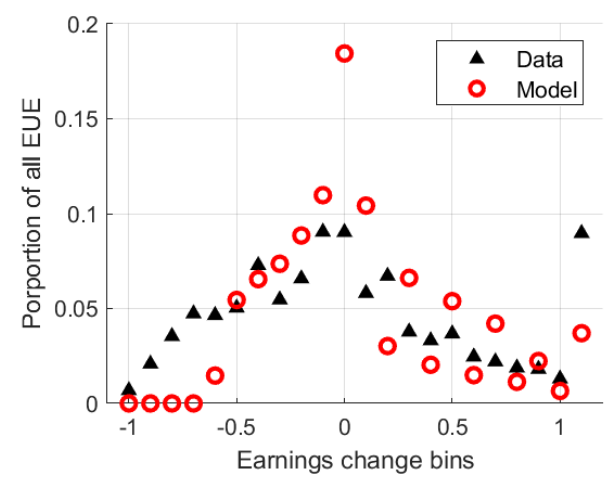

Note: Earnings changes are calculated as ratios of pre-unemployment wages, i.e. (post-unemployment wage pre-unemployment wage)/pre-unemployment wage. Each bin groups earnings changes of 0.1 , with center of bin marked on x-axis, except for the last bin which contains changes $>=1.05$. Data of earnings change come from SIPP

2004 panel, for all employment-unemployment-employment episodes with re-employment during 2005-2007.

shaped distribution centered around 0, similar to the data (black triangle). Compared to the data, the model generates too many EUE episodes with little change in earnings (in bin marked 0, i.e. earnings changes -0.05 to 0.05 ), and too few episodes with large earnings drop or gain (more than $50 \%$ drop or more than $100 \%$ rise).

\subsection{Policy effects at steady state}

To look at the steady state effects of the retention policy, I compare the steady state economies under different policy regimes: no UI extension; with UI extensions but no retention policy, so temp workers who do not re-qualify for new benefits have no benefits; with extension and retention policies, so temp workers who re-qualify for new benefits forfeit any uncollected old benefits; and 
finally, extension, retention and the Federal law of July 2010, where temp workers can choose between new and uncollected old benefits if they re-qualify for a new UI segment. All parameters are the same across the economies and at the calibrated values of the 2012 economy.

Individual job decisions It is easier to understand the mechanisms in stationary economies when fewer things are moving. As such, I first show the policy functions for the decision to accept/reject a temp job. ${ }^{31}$ Figure 5 plots, for each of the policy scenarios, the types of unemployed workers who reject a temp job. The bottom right economy is the one used to calibrate the 2012 economy, with UI extension, retention and federal law.

In each plot, the x-axis marks the UI benefit level. Benefit level of 1 means the individual previously held a temp job. Benefit levels greater than 1 correspond to benefits qualified from regular jobs, each number corresponding to one bin in the wage distribution. ${ }^{32}$ The $y$-axis marks the UI periods used (in weeks). A larger number means the individual is closer to UI exhaustion. The shaded regions represent the worker types who would reject a temp job. The blue horizontal line marks the maximum UI entitlement.

There are two reasons for an unemployed worker to turn down a temp job which are common across all four policy regimes. First, by turning down a temp job the unemployed worker can wait for a better job offer next period. The value of waiting is strongest at the start of a UI spell, but as UI benefit comes close to exhaustion, more unemployed workers take temp jobs. This is why the lower regions are mostly shaded in the plots, whereas higher up close to the maximum UI entitlement, there is more job take-up (not shaded). Workers do not wait until the last week of UI entitlement to accept a temp job because job arrival and the type of job that arrives (temp or regular, wages) are stochastic. There may not be better or any job offers next period. A worker is more willing to wait close to UI exhaustion if the base consumption in unemployment without UI $(\underline{c})$ is larger, the job arrival rates $\left(\rho\right.$ and $\left.\rho_{g}\right)$ are higher, or the wage distribution of regular jobs $(f(\mathbf{w}))$ becomes more skewed to the right.

Second, an unemployed worker turns down a temp job if her benefit level is higher than the wage offered. This is the case only for the highest wage bin (benefit level 11). Additionally, unemployed workers with higher benefits (but not necessarily higher than temp wage) are more likely to turn down the job to wait for a better offer because their consumption gain from employment is lower. This is why the right regions are mostly shaded in the plots. For the same reasons, those with higher benefits are more likely to wait longer, which is why the shaded regions in the plots mostly slope upward to the right - all except for level 2 benefit which corresponds to the lowest wage level of a regular job and is lower than the temp wage.

Comparing across the policy regimes, proportionally more unemployed workers turn down temp

\footnotetext{
${ }^{31}$ Some unemployed workers also reject lower-paid regular jobs. Across the policy regimes, rejection of regular jobs is mostly the same. So the key margin of difference on the individual level is the decision to take up or reject temp jobs.

${ }^{32}$ In the calibrated model, unemployed workers without UI benefits never reject a job.
} 
Figure 5: Comparison of temp job rejections across steady state economies in 2012.
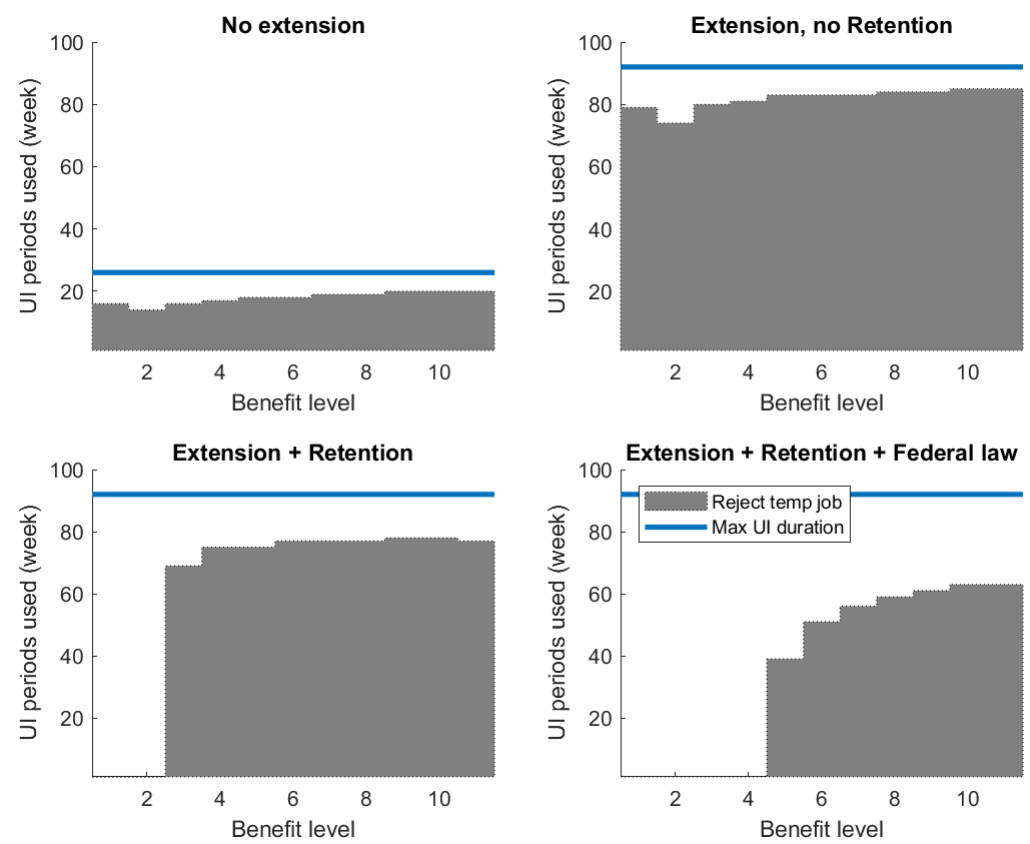

Note: Plots show the decision rule $J o b_{b}(\omega, j)$ for each policy scenario. The types of unemployed worker — by benefit level (x-axis) and UI periods used (y-axis) — who reject a temp job offer in a steady state economy are shaded. Benefit level $=1$ when old job was temp job, benefit level = 2 to 11 corresponds to each of the ten bins of regular wages. The lowest regular wage (level 2) is lower than temp wage (level 1). Blue horizontal line marks the maximum UI entitlement in the economy.

jobs when UI extensions are introduced. Without the retention policy, unemployed workers in the first few weeks of their current UI spell turn down temp jobs. With the retention policy, those with relatively low benefit levels always take a temp job, independent of how many periods of the current UI spell they have used. With the retention policy, any unused UI entitlements are 'stored' for their next unemployment if they do not re-qualify for a new spell. The additional federal law further increases the temp job accepting range to include those with middle range of benefit levels, because these unemployed workers can now choose between new and unused old UI spells.

Distributional effects Different policy regimes also have distributional effects on the type of unemployed workers in the steady state. Figure 6 compares the distribution across policy regimes along two dimensions: benefit level (left plot) and UI entitlement used of the current spell (right plot). Each line represents one steady state economy with a different policy regime, and the percent density on a line sums up to $100 \%$.

A UI extension from 26 to 92 weeks increases the proportion of unemployed workers with higher benefit levels and raises the proportion of unemployed workers who are close to UI exhaustion (com- 
Figure 6: Comparison of the distribution of unemployed workers across steady state economies in 2012.
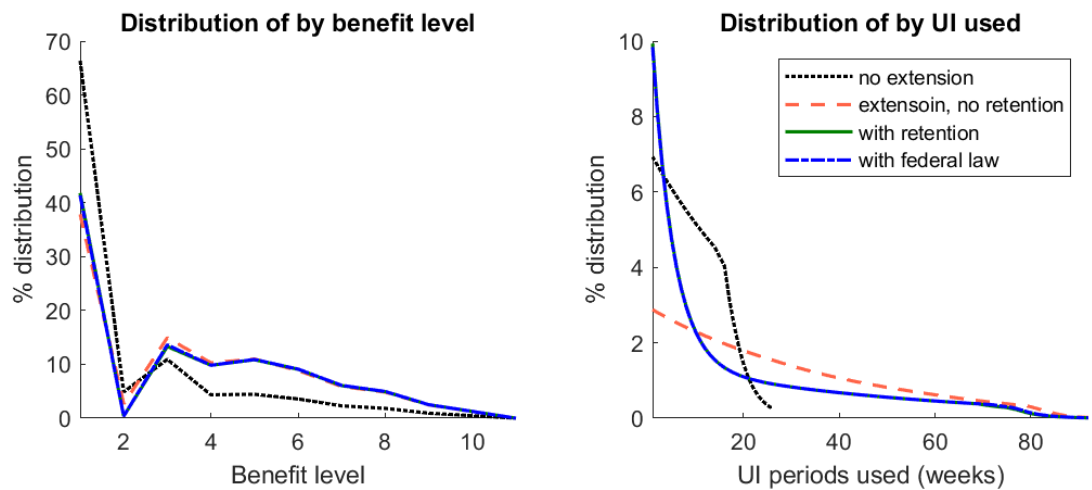

Note: Plots show the percent distribution of unemployed workers for each benefit level (left) or for different levels of UI entitlement left (right). Each line represents the steady state economy with a different policy regime, and the total density on a line sums up to $100 \%$.

paring the dotted black line with the broken red line), because extensions allow the unemployed workers to wait longer for better job offers.

The retention policy most notably increases the proportion of unemployed workers who have used only a few periods of current UI spell (comparing the broken red line with the solid green line). With the retention policy, more unemployed workers take up temp jobs which have short expected tenures, so there are proportionally more unemployed workers who are freshly unemployed. In other words, there are more workers in the economy who transition into and out of unemployment very quickly.

Figure 7: Effect of federal law: Distributional difference of unemployed workers.

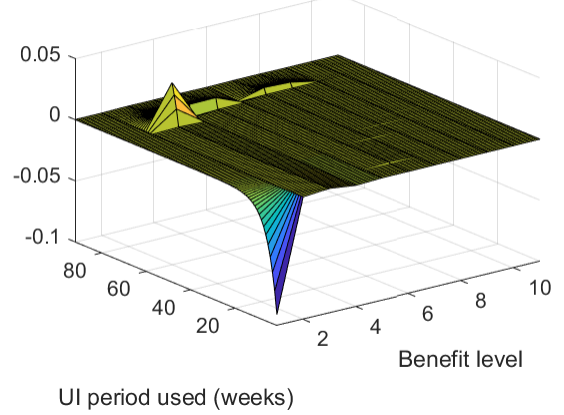

Note: Plot shows the distributional effect of the federal law for unemployed workers over benefit level and UI periods used. Distribution measure is computed as (density of the steady state economy with federal law - density of the steady state economy without federal law)/total density without federal law $\times 100 \%$.

To better showcase the distributional effect of the federal law on top of the retention policy, I plot the differences in density between the economies with and without the federal law, for each type of unemployed workers by benefit level and UI periods used. Figure 7 shows that the federal law 
Figure 8: Effect of federal law: Temp workers choosing old benefits.

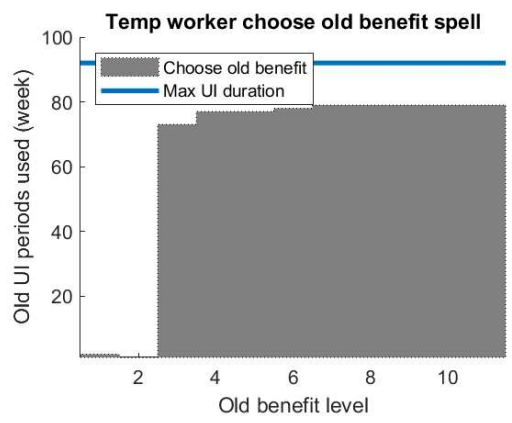

Note: Plot shows the decision rule Fix $(\omega, j)$. The types of temp workers - by old benefit level (x-axis) and old UI periods used (y-axis) - who choose the leftover of their old UI spell rather than newly qualified UI spell in a steady state economy are shaded. Benefit level $=1$ when old job was temp job, benefit level $=2$ to 11 corresponds to each of the ten bins of regular wages. Blue horizontal line marks the maximum UI entitlement in the economy.

reduces the proportion of unemployed workers with low benefit levels and at the first few periods of their UI spell (the blue downward spike). The federal law increases the proportion of those with higher benefit level and close to the end of the current UI entitlement (the green upward spikes). These distributional effects are present because many unemployed workers choose the old spell with higher benefit level and fewer entitlement periods left. This can be seen also in Figure 8 which plots the choice between new and old UI spells for temp workers: Workers with higher old benefit level and at least about 10 weeks away from UI exhaustion on their old UI spell choose the old benefits (shaded region).

Table 4: Comparison of steady state economies in 2012.

\begin{tabular}{lcccc}
\hline \hline & No extension & $\begin{array}{c}\text { Extension, } \\
\text { no retention }\end{array}$ & $\begin{array}{c}\text { Extension }+ \\
\text { Retention }\end{array}$ & $\begin{array}{c}\text { Extension }+ \\
\text { Retention }+ \\
\text { Federal law }\end{array}$ \\
\hline Job finding rate(\%) & 9.79 & 5.04 & 12.53 & 17.90 \\
Unemployment rate(\%) & 7.11 & 9.60 & 9.21 & 8.67 \\
\% Workers on temp job & 5.71 & 2.94 & 12.50 & 18.08 \\
\hline
\end{tabular}

Note: Table reports aggregate statistics in each of the four steady state economies. The last economy with extension, retention policy and federal law is calibrated to the economy of 2012 . The other three economies are counterfactuals with alternative policy regimes while holding all other parameters unchanged.

Aggregate effects Table 4 compares the aggregate economies under different policy regimes. The UI extension from 26 to 92 weeks lowers job finding rate, raises unemployment by 2.5 percentage points, and reduces the proportion of workers on temp jobs as more unemployed workers wait around for better job offers. With the retention policy more workers are willing to take up temp jobs, so the overall job finding rate increases by 7.5 percentage points, and the proportion of workers on temp 
Figure 9: Paths of time-varying parameters 2008-2012.
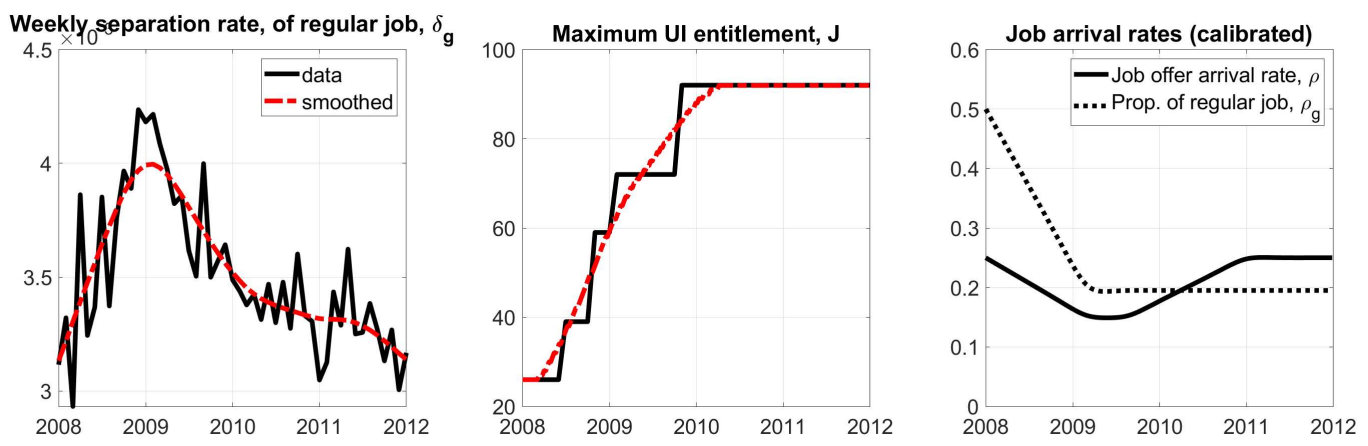

Note: Plot shows the paths for the exogenous time-varying parameters which are inputs into the transitional economies from 2008 to 2012. Separation rates $\delta_{g}$ and maximum UI entitlements $J$ are taken from data and smoothed. Job arrival rates $\rho$ and $\rho_{g}$ are calibrated to match statistics.

jobs increases by 9.6 percentage points. At the same time, because temp jobs have short expected tenures, workers leave jobs much more frequently. As a result, the retention policy only reduces unemployment by 0.39 percentage points. Similarly, with the introduction of the federal law, even more workers take up temp jobs instead of waiting around for better offers, so the overall job finding rate and the proportion of workers on temp jobs increase even further, and unemployment rate drops by 0.54 percentage points.

\subsection{Policy effects over transition path}

To evaluate the policy effects during the recession, I compute the transition path between the two steady states. The initial steady state resembles the pre-recession economy of 2005-2007 without UI extensions, The end steady state is the economy of 2012 when both the job separation rates and UI extensions have stabilized and the economy is approximately at a steady state.

Time-varying parameters Over the transition path between the two steady states, the job arrival rates, $\rho_{t}$ and $\rho_{g, t}$, the regular job separation rate, $\delta_{g, t}$, and the maximum potential UI entitlement, $J_{t}$, change over time. When computing the transition path, I assume that the paths of the timevarying parameters are revealed at the start of the transition path. In other words, it is a perfect foresight transition given these exogenous paths. The assumption of perfect foresight makes solving the transition path computationally manageable. ${ }^{33}$

Figure 9 shows the paths of the exogenous processes from 2008 to 2012. The path for the maximum UI entitlement is taken directly from the U.S. Department of Labor Employment and Training Administration (DOLETA) website. I smooth the regular job separation and UI entitlement

\footnotetext{
${ }^{33}$ Appendix C provides more details on the computational algorithm, which is similar to Conesa and Krueger (1999) and Nakajima (2012) without prior announcement of policy changes.
} 
Figure 10: Comparison of transitional economies, 2008-2012.
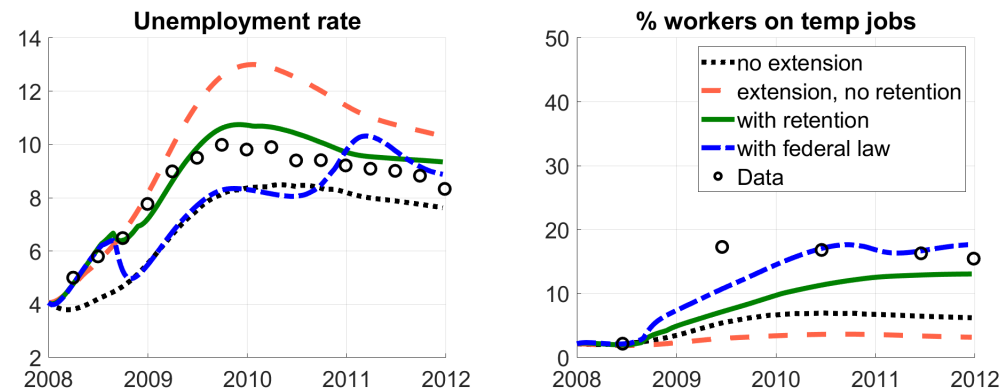

Note: Plot shows the unemployment rate and proportion of workers on temp jobs in the transitional economies from 2008 to 2012 under different policy regimes. Each line represents a different transitional economy. Dots represent data counterparts.

series before feeding them into the model to compute the transition path. Using the smoothed series makes the assumption of a transition path with perfect foresight more reasonable. ${ }^{34}$

The paths for the proportion of regular jobs $\rho_{g, t}$ and the job arrival rates $\rho_{t}$ are jointly pinned down to match the proportion of EUE spells with negative earnings changes (0.45) and the unemployment rate $(10 \%)$ in the second half of $2009 .{ }^{35}$ This requires job arrival rates (solid black line) to drop from 0.25 to 0.15 in 2009 before recovering to the pre-recession level, and the proportion of regular jobs among job offers (dotted black line) to fall from 0.5 to 0.195 in 2009 and stay low. ${ }^{36}$

Policy experiments Given the initial (2005-2007) and end (2012) steady states and the time-varying parameters during transition, Figure 10 plots the transition paths under different policy regimes. Each line represents one transitional economy from the same initial steady state economy and ends in different steady state economies but otherwise experience the same time-varying parameters (except for UI extensions for the economy without extensions). I assume policy differences are revealed at the start of the transition path. The economy with extension and retention policies (solid green line) should be the closest to the real economy up until mid-2010 when a different policy regime (with federal law) was implemented. And the gap between two lines captures the policy effect. I additionally plot the data counterparts of unemployment rates and proportion of workers on temp jobs.

\footnotetext{
${ }^{34}$ It would be hard to imagine that the workers and firms perfectly foresee the exact scale and timing of changes in UI entitlement in Figure 9 or the short-term fluctuations in the job separation rates. It is more reasonable to think of workers forming expectations about the general paths of UI extension and job separation risks.

${ }^{35}$ Since the peak of unemployment around the second of 2009 is before July 2010 when the federal law came into effect, I use the model-generated moments on the transition without federal law. This is consistent with the federal law being unanticipated.

${ }^{36}$ The calibrated $\rho$ and $\rho_{g}$ values mean the job arrival rates for both temp and regular jobs are lower during the peak of the recession (2009) than either before (2005-2007) or after (2012). The calibrated temp job arrival rate in 2009 is $0.15 * 0.805=0.1207$ lower than both the initial steady state $(0.25 * 0.5=0.125)$ and the end steady state $(0.25 * 0.805=0.2013)$. Similarly, the calibrated regular job arrival rate in 2009 is 0.0292 , lower than the initial steady state (0.125) and the end (0.0488).
} 
Consistent with the findings for the steady state economies, UI extension raises both unemployment rate and proportion of workers on temp jobs. Introducing the retention policy at the start of the transition raises the proportion of temp workers and lowers unemployment relative to the economy without the retention policy. Implementing the federal law on top of the retention policy from the start further raises the proportion of temp workers and lowers unemployment pre-2010.

Over the transition path the policy effects on unemployment are amplified. For example, the retention policy reduces unemployment rate by up to 2 percentage points over the transition (comparing the broken red line to the solid green line), whereas in the end steady state the difference is only 0.39 percentage point. Similarly, the federal law also has a larger effect on unemployment at the peak of the recession (the dashed blue line compared to the solid green line) than in the steady state. To better understand what drives the amplification, I decompose the policy effects by introducing one time-varying parameter at a time.

Decomposing effects of time-varying parameters I look at a set of transitional economies with one time-varying parameter at a time $\left(\delta_{g}, \rho, \rho_{g}\right)$ while holding all others constant (except for UI extensions $J$ ). All transitions still start from the same initial steady state as before, but the steady state economy at the end of the transition is different from before.

Figure 11 shows that the proportion of regular jobs $\rho_{g}$ is important for amplifying the unemployment effects of the retention policy as well as the federal law. $\rho_{g}$ is also key to generating differences in the proportion of temp workers. Intuitively, a high value of $\rho_{g}$ pre-recession means there are many workers with relatively high wages entering the recession, and these are the people most affected by the retention policy. During the recession, when $\rho_{g}$ is lower, many job offers are temp jobs with relatively low wages, so many unemployed workers have to decide whether to take temp jobs. The high level of $\rho_{g}$ pre-recession and low level during the recession together generate large retention effects both with and without the federal law.

\section{EXTENSIONS}

This section discusses some extensions to the quantitative model of the previous section. Appendix $\mathrm{D}$ contains the full setup and results of these alternative specifications.

\subsection{Additional features of the UI system}

UI benefit with upper bound In the baseline model, UI benefits are proportional to the most recent wages $(\gamma w)$. In the U.S. benefit level is subject to an upper bound. An alternative to the baseline specification is to set weekly benefit to $\max \{\gamma w, \bar{b}\}$. In other words, workers with wages $w>\bar{b} / \gamma$ have benefits lower than $\gamma w$ when they are unemployed. Most U.S. states set the maximum weekly benefit amount at around $\$ 400$ in 2008. A quick back-of-the-envelop calculation shows none of the 
Figure 11: Decomposing effects of parameters $\left(\delta_{g}, \rho, \rho_{g}\right)$ over transition, 2008-2012.

(a) Only changing regular job separation rates $\delta_{g}$
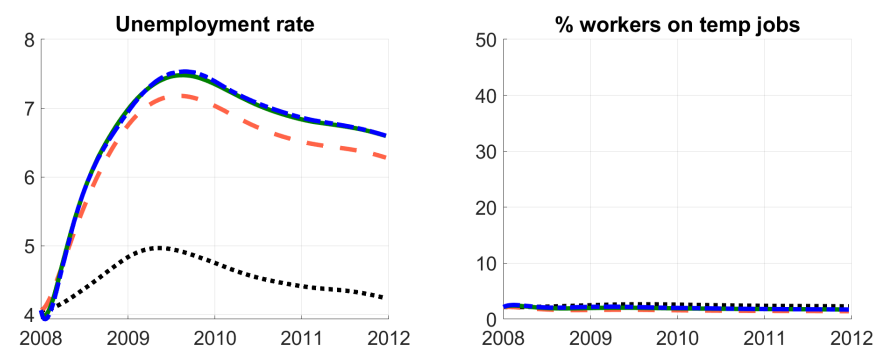

(b) Only changing job arrival rates $\rho$
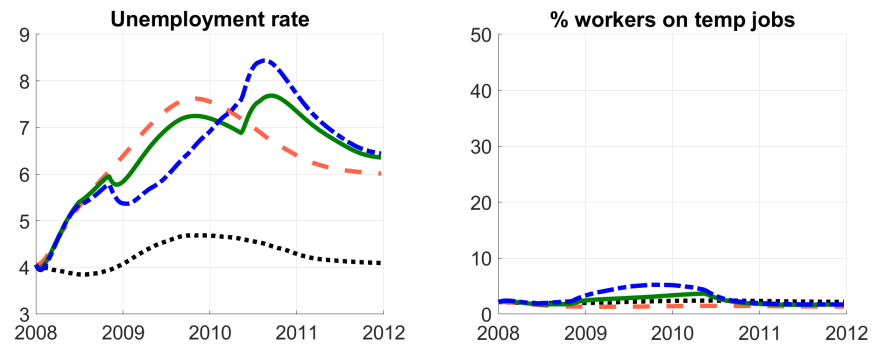

(c) Only changing prop. of regular jobs among offers $\rho_{g}$
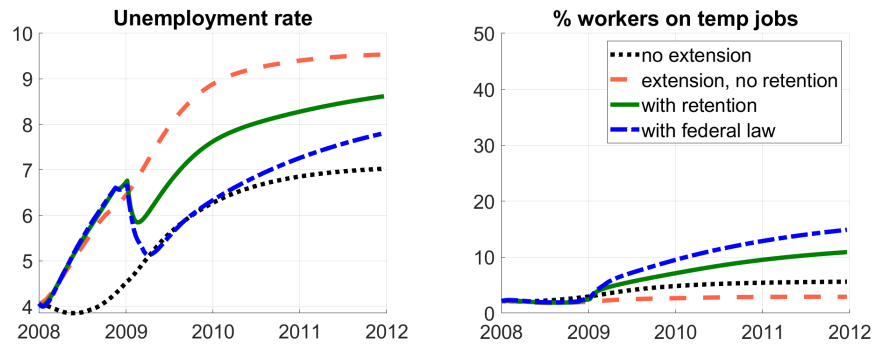

wages in my range hit the upper bound: $\$ 400$ weekly benefits converts to $\$ 1000$ weekly earnings. Using a weekly working hour of 40 hours gives $\$ 25$ hourly wages, which is approximately 1.25 on the normalized scale ( $\$ 7.02$ being 0.35 ), much higher than the 0.95 upper bound on the regular job wage range used in the model, which is the $80^{\text {th }}$ percentile of wages in the data.

Temp job qualifies for shorter UI benefits The standard benefit duration is 26 weeks. Nine states provide a uniform potential duration of 26 weeks to all recipients who qualify for UI benefits. The remaining states adopt variable duration policies whereby the entitled duration is based on the recipients' most recent work experience. In the baseline quantitative model, I assume all unemployed workers who qualify for UI are automatically entitled to the full 26 weeks (and extensions accordingly). As an alternative, I assume here that workers newly unemployed from temp jobs qualify for 
shorter durations ('partial UI') with $J(\underline{w})=2 J / 3$, and consistently with the implementation of UI extensions, the extensions are also lower for these workers.

Appendix D.1 contains the results for this specification. Without re-calibrating the model, I show the changes in individual's job decision compared to the baseline model. Because workers who had temp jobs qualify for shorter UI entitlement, they accept temp jobs sooner than in the baseline to avoid running out of benefits. This change in individual choice raises overall job finding rate, lowers unemployment and raises the proportion of workers on temp jobs in the steady state economies without the retention policy. In the economy without extensions, the job finding rate rises from $9.79 \%$ to $12.46 \%$, unemployment falls from $7.11 \%$ to $5.99 \%$, and the proportion of workers on temp jobs rises from $5.7 \%$ to $6.3 \%$; similarly for the economy with extension but without the retention policy. In the economies with the retention policy, these same workers accept a temp job regardless of UI entitlement, and so introducing partial UI has no effect on the aggregate economies. With the partial UI, the effects of different policy regimes during the transition are also similar to the baseline results.

\subsection{Saving and borrowing}

Worker's ability to borrow and save can be important for the impact of UI policy. Saving and borrowing provides partial self-insurance against business cycles and policy changes. As it substitutes for the consumption smoothing effect of the retention policy, the effect of the policy should be smaller when saving and borrowing are allowed. I augment the quantitative model to include a choice to save/borrow each period subject to a borrowing constraint, which I set to -0.2 (some borrowing) or 0 (no borrowing). I keep the rest of the parameters the same as in the quantitative baseline to show any differences from the baseline model. Details of the asset model and steady state results are included in Appendix D.2.

Consistent with intuitions, across all policy regimes, unemployed workers with higher asset levels wait longer before accepting a job. This is especially so at low benefit levels. For example, with UI extension but no retention policy, unemployed workers with the lowest benefit level (level 2) and lowest asset level accept a temp job whenever it arrives, whereas those with the same benefit level but the highest asset level would wait until they have used 80 weeks of UI before accepting the job.

Compared with the model without saving and borrowing, the unemployed workers with the highest asset level here are always more likely to turn down a temp job given the same UI benefit

level. Those with the lowest asset level are less likely to turn down a temp job than in the baseline (without asset) if their benefit level is low. But if their benefit level is high, then allowing saving and borrowing delays their job take-up. This is the same whether I allow some borrowing so the lowest asset level is negative, or no borrowing. With high benefit levels the unemployed worker can save up while collecting benefits, and this saving creates a buffer against low consumption when benefits 
run out, allowing them to wait longer for a better job offer.

Comparing across policy regimes, the directions of the policy effects on individual's job decisions are the same as in the baseline, but the sizes of the effects are smaller. Specifically, both the retention policy and the federal law have stronger effects on unemployed workers with lower asset levels. But even for these workers, the effects of policies are smaller than in the baseline model.

Because of the weaker effects of the retention policy on the individual level, the aggregate policy effects are also smaller. For example, introducing the retention policy in a steady state increases the overall job finding rate by 3 percentage points compared to 7.5 percentage points in the baseline. Because of the smaller gain in job finding rate, unemployment rate increases instead of falls, as an increased proportion of temp jobs in the economy raises the average job separation rates. Similarly, introducing the federal law on top of the retention policy raises the overall job finding rate by 0.5 percentage point in the economy with borrowing and saving, compared to 5.43 percentage points in the baseline. ${ }^{37}$

One caveat to the quantitative results is the calibrated model does not try to match the joint employment-wealth distribution in the data. Many of the unemployed workers likely have very low levels of liquid assets, especially during the Great Recession. This means the proportion of creditconstrained unemployed workers in the data is likely larger than in the calibrated model here. Because those with low asset levels are affected more by the retention policy, in a model with realistically calibrated wealth distribution, the policy effects would be stronger, and unemployment could be lower with the introduction of the retention policy.

\subsection{Alternate assumptions on the labor market}

Job quits One reason that workers turn down temp jobs in the model is the optional value of waiting, which works because of the underlying assumption of no quitting from a job. In the model, with stochastic job separation and UI qualification, a worker would not take a job if she expects to quit later. But with deterministic UI re-qualification, a temp worker's continuation value changes with periods worked. As a result, with the retention policy a worker may accept a temp job and

\footnotetext{
${ }^{37}$ In Appendix D.2 I include a set of plots to show the distributional effects of various policies, similar to Figure 6 in the baseline. I plot the percent distribution of unemployed workers over benefit level and over UI periods used, separately for the bottom 5 asset levels (low asset group) and the top 5 asset levels (high asset group). A few interesting effects are worth noting. First, for the low asset group, without UI extensions, the unemployed workers are very likely to end up in the lower benefit level; with UI extensions, they are more likely to be unemployed with higher benefit levels. This is because the unemployed workers with low asset levels cannot effectively smooth consumption between unemployment with and without benefits, and as a result, they accept a temp job too soon, and once unemployed again they end up with the low benefit level; UI extensions allow these people longer time to wait for a better offer and increases their chances of getting a better job offer. Second, the distribution of unemployed workers in the high asset group is mostly unaffected by different policy regimes. Curiously, over UI periods used, the high asset group concentrates around the first 10 periods, which indicates that regardless of the policy regime, they find jobs very quickly. This is partly an equilibrium outcome: high asset levels are positively correlated with shorter time spent in unemployment, because the workers who find jobs faster can accumulate more savings while they work.
} 
quit right before she re-qualifies for new benefits in order to preserve her old benefits. In practice in the U.S., a worker who voluntarily quits from her job without a 'good cause' is not eligible to collect unemployment benefits. Temp workers, arguably with less resource, are less likely to quit if quitting means they cannot collect unemployment benefits. Among workers on short-term (less than four months tenure) jobs in the SIPP 2008 panel, 20-25\% of job separations are because of quitting, compared to $40-50 \%$ among long-term job workers ( $\geq 12$ months job tenure). ${ }^{38}$

To see how quitting works in the model, I allow workers on temp jobs the decision to quit and still be eligible to collect and retain benefits. Results are included in Appendix D.3. Regular job workers do not have incentives to quit. In general, a worker quits if the continuation value of working is lower than the future value of quitting into unemployment. This happens if future unemployment is likely (e.g. high job separation rate), and the value of unemployment now is high enough relative to the value of unemployment later (e.g. if benefits are higher by quitting now). This is not the case in the calibrated economies of 2012 without the retention policy, and so no one quits and the job take-up decisions and the aggregate economies are identical to those in the baseline.

With the retention policy, however, workers do quit. Interestingly, because of the option to quit, unemployed workers are more likely to accept a temp job in the economy without the federal law, because they can always quit before re-qualifying for new lower benefits. As a result, the overall job finding rate is higher in this economy compared with the baseline (18.07\% vs $12.53 \%)$. There are proportionally more temp workers in this economy (13.5\% vs 12.5\%), and unemployment rate is slightly lower (9.12\% vs $9.21 \%)$ than in the baseline.

Overall, the retention policy increases the job finding rate, reduces the unemployment rate. The federal law on top of the retention policy further raises the job finding rate and lowers unemployment, consistent with the baseline results.

Wage dispersion in temp jobs In the baseline model temp jobs all offer the same wages, while regular jobs offer a wide range of wages. As an extension, I introduce a (small) range of wages for the temp job as well. In particular, a temp job wage offer takes one of three values: $\{0.3,0.35$ (baseline value), 0.37$\}$ with probabilities $[0.25,0.5,0.25]$. The rest of the parameters are kept the same as in the baseline. Note that the lowest wage of a regular job (0.33) is lower than the two highest wages of a temp job, the rest of the regular job wages are higher than all temp wages. Appendix D.4 contains the results.

On the individual level, most unemployed workers turn down temp jobs with the lowest wage level, and policy has very small effects here. The retention policy and the federal law do have significant effects on the decision to accept temp jobs with the highest wage level. Overall, the effects of policy is smaller than in the baseline. The retention policy increases the overall job finding

\footnotetext{
${ }^{38} \mathrm{SIPP}$ reports reason for job separation. I code a separation as because of quitting if the reported reason is "Quit to take another job", "Unsatisfactory work arrangements" or "Quit for some other reason"; separation is not because of quitting if the reason is "On layoff", "Discharged/fired", "Employer bankrupt", "Employer sold business", "Job was temporary and ended", or "Slack work or business conditions". I drop the separations from this calculation if the reported reason indicates the workers is temporarily or permanently out of labor force, .e.g "Retirement or old age", "Childcare problems".
} 
rate by 2.34 percentage points compared to 7.5 percentage points in the baseline. As a result, unemployment increases with the introduction of the retention policy, as the increase in the average job separation rate offsets the relatively small increase in overall job finding rate. Introducing the federal law increases the job finding rate further and lowers unemployment rate, but unemployment is still higher than the economy without the retention policy.

Note that the quantitative effects of policy depend on the range and distribution of the temp job wage offers. In general, the retention policy increases job finding rate more if the wage offer has a bigger range or if the distribution is more concentrated in the center.

Human capital depreciation Human capital depreciation during unemployment potentially reduces future wages, and as a result, unemployed workers have an additional incentive to find a job sooner rather than later. Whether and how human capital changes the estimated effects of the retention policy will depend on how human capital accumulates and depreciates, for example, whether working on a temp job reduces human capital stock, and how specific is human capital to a (type of) job.

The gain in human capital from continued employment is likely small in the short and medium term, and especially so during recessions. Using the SIPP 2008 panel I estimate the effect on hourly wage (or monthly earnings) of two types of human capital: the short-term (the observed number of periods that a worker has worked up to time t) and the long-term (the potential experience of a person up until time t). I control for demographics, whether the worker has had an unemployment

spell, the worker's industry, and the monthly unemployment rate of her state of residence. The regression results in Appendix D.5 show that the short-term human capital stock has about $60 \%$ of the effect of the long-term human capital. An additional month of the long-term human capital is associated with $\$ 15$ additional monthly earnings or $\$ 0.5$ more in hourly wages, whereas an additional month in the short-term human capital is associated with $\$ 9.7$ additional monthly earnings or $\$ 0.3$ more in hourly wages.

Because of the relatively small effects, and the fact that the human capital process for temp jobs lack empirical discipline, I abstract from the human capital aspect in the analysis here.

\section{Conclusion}

This paper investigates an unemployment benefit policy that allows the unemployed workers to delay the collection of benefits to future unemployment spells (the retention policy). I first document that during recessions in the U.S. workers can and do take advantage of the policy when they are offered a short-term job. Exploiting policy variations over time and across U.S. states, I then present evidence that allowing workers access to delayed benefit collection encourages job take-up. Intuitively, the 'saved' benefits help smooth consumption between two unemployment spells and encourage unemployed workers to take low-paying, short-term jobs.

I then build a quantitative model where the unemployed workers choose to accept/reject a job 
depending on their current benefit level, UI entitlement left, and the nature of the job (wage level, expected job tenure). I incorporate institutional details consistent with the retention policy, and show the effects are consistent with expectations. In a wide range of extensions that the retention policy increases the overall job finding rate in the steady state stationary economy. The policy has varying effects on unemployment rates, depending on the relative scale of the effects on job finding rates. In a calibrated version of the transitional economy from 2008 to 2012, the retention policy lowers the unemployment rate by up to $2 \%$, mitigating the negative effects of UI extensions.

\section{REFERENCES}

Auray, S., D. L. Fuller, and D. Lkhagvasuren (2019): "Unemployment Insurance Take-up Rates in an Equilibrium Search Model," European Economic Review, 112, 1-31.

Cheтty, R. (2008): "Moral Hazard Versus Liquidity and Optimal Unemployment Insurance," Journal of Political Economy, 116, 173-234.

Chodorow-Reich, G., J. Coglianese, and L. Karabarbounis (2018): "The Macro Effects of Unemployment Benefit Extensions: A Measurement Error Approach," Quarterly Journal of Economics, 134, 227-279.

Conesa, J. C. And D. Krueger (1999): "Social Security Reform with Heterogeneous Agents," Review of Economic Dynamics, 2, 757-795.

Cullen, J. B. And J. Gruber (2000): "Does Unemployment Insurance Crowd Out Spousal Labor Supply?" Journal of Labor Economics, 18, 546-572.

Department of Labor (2015): "Chronology of Federal Unemployment Compensation Laws," .

Fujita, S. (2010): "Effects of the UI Benefit Extensions: Evidence from the CPS," FRB Philadelphia Working Paper No. 10-35/R.

Hagedorn, M., F. Karahan, I. Manovskit, and K. Mitman (2015): "Unemployment Benefits and Unemployment in the Great Recession: The Role of Macro Effects," National Bureau of Economic Research Working Papers 19499.

Jung, P. And K. Kuester (2015): "Optimal Labor-Market Policy in Recessions," American Economic Journal: Macroeconomics, 7, 124-156.

Krueger, A. And B. Meyer (2002): "Labor Supply Effects of Social Insurance," in Handbook of Public Economics, ed. by A. Auerbach and M. Feldstein, Amsterdam: North-Holland.

Krueger, A. B. And A. Mueller (2010): "Job Search and Unemployment Insurance: New Evidence from Time Use Data," Journal of Public Economics, 94, 298-307. 
LaLumia, S. (2013): "The EITC, Tax Refunds, and Unemployment Spells," American Economic Journal: Economic Policy, 5, 188-221.

McCall, B. P. (1970): "Economics of Information and Job Search," Quarterly Journal of Economics, 84, 113-126.

Mitman, K. and S. Rabinovich (2015): "Optimal Unemployment Insurance in an Equilibrium Business Cycle Model," Journal of Monetary Economics, 71, 99-118.

NAKajima, M. (2012): "A Quantitative Analysis of Unemployment Benefit Extensions," Journal of Monetary Economics, 59, 686-702.

PEI, Y. AND Z. XIE (2016): "A Quantitative Theory of Time-Consistent Unemployment Insurance," Manuscript, University of Minnesota.

Ríos-Rull, J.-V. (1999): "Computation of Equilibria in Hetergeneous-Agent Models," in Computational Methods for the Study of Economic Dynamics, ed. by R. Marimon and S. Andrew, Oxford: Oxford University Press.

Rothstein, J. (2011): "Unemployment Insurance and Job Search in the Great Recession," Working Paper.

Shimer, R. (2005): "The Cyclical Behavior of Equilibrium Unemployment and Vacancies," American Economic Review, 95, 25-49.

Zhang, M. And M. FAIG (2012): "Labor Market Cycles, Unemployment Insurance Eligibility, and Moral Hazard," Review of Economic Dynamics, 15, 41-56. 


\title{
Online Appendix for "Delayed Collection of Unemployment Insurance in Recessions"
}

\author{
Zoe $\mathrm{Xie}^{39}$ \\ Federal Reserve Bank of Atlanta \\ Email: xiexx196@gmail.com
}

\footnotetext{
${ }^{39}$ The views expressed in this paper are those of the authors and do not necessarily represent the views of the Federal Reserve System or the Federal Reserve Banks.
} 


\section{A Example of policy variations across U.S. states}

This section provides an example to illustrate the cross-state difference in retention policy. The example here complements the discussion in Section 2.1.

Figure A1: Illustration of cross-state difference in retention policy.

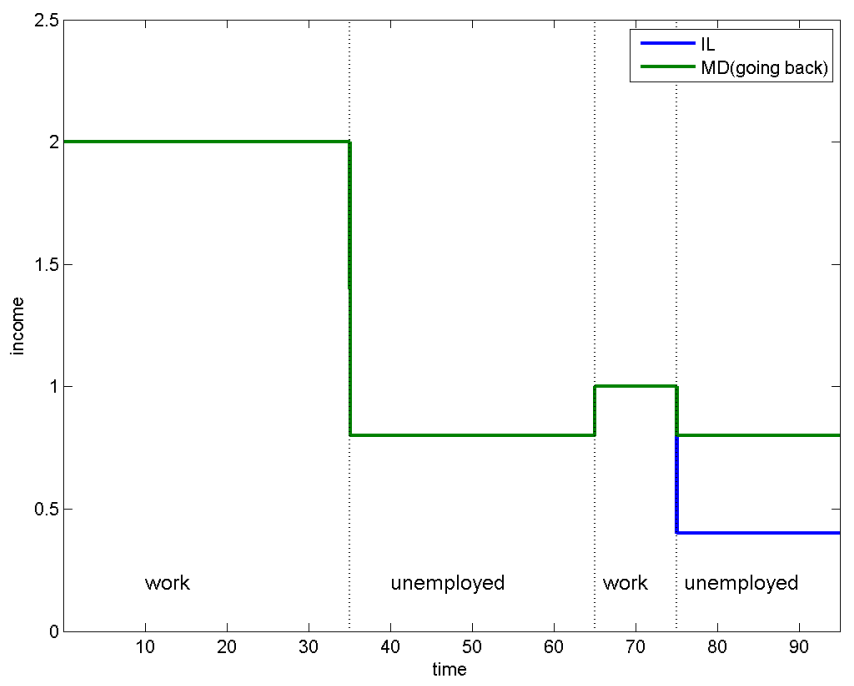

This example illustrates how cross-state differences in income requirement for UI re-qualification affect benefit collection. Figure A1 compares two states. The example follows a worker who becomes unemployed twice within a 95-week period. Her first work spell (weeks 1 to 35) is long and wages are high. This is analogous to pre-recession times. Her second work spell (weeks 65 to 75 ) is short and wages are lower, which mimics what happens in a bad labor market where good jobs are few and separation rates are high. The unemployment income (UI benefits) is determined by (1) the wages of her most recent work spell; and (2) whether or not she re-qualifies for new benefit segment during the second unemployment spell. Because her wages during the second work spell is lower, her benefits (if she re-qualifies for a new benefit segment) is much lower during the second than the first unemployment spell.

For illustrative purpose, suppose Illinois (blue line) has a very low income requirement such that the worker can more easily re-qualify for new benefits, which are lower than her previous benefits. As a result, the worker cannot collect at the higher previous benefit level. In contrast, Maryland (green line) has a higher income requirement for UI re-qualification, which makes it harder for her to re-qualify for new benefits and easier to continue collecting the leftover benefits from the first unemployment spell.

Anticipating the difference in income level during the second unemployment spell, workers have different work incentives during the first unemployment spell. In Maryland, where the expected 
income during the second unemployment spell is relatively high, the worker has more incentives to find any job. In contrast, in Illinois, she is more cautious (or picky) about jobs, because working for low pay re-qualifies her for lower benefits, which is worse than not working and collecting the higher benefits from her first benefit segment. Following this logic, the probability that an average worker finds a job within a set period of time will be higher in Maryland than in Illinois. Note that in addition to benefit level, the duration of benefits is also a factor in the worker's choice. Because newly qualified benefits start from week 1, the duration on the new UI segment is most likely longer than any uncollected old benefits. In the quantitative model I take into account this difference by modeling deterministic UI exhaustion. 


\section{B State-level re-employment probability measures by year}

This section supplements the state-level empirical analysis and presents state-level re-employment probability by year. Consistent with state-level analysis shown in Section 2.2, before 2010 the reemployment probability among unemployment spells that ever received UI (left plot) is higher in states where it is easier to collect previous benefits: group 3 (green cross) has higher re-employment probabilities than group 2 (orange circle) than group 1 (blue triangle). After 2010 or among spells that never received UI (right plot) there is no consistent pattern.

Figure A2: State-level re-employment probability measures by year
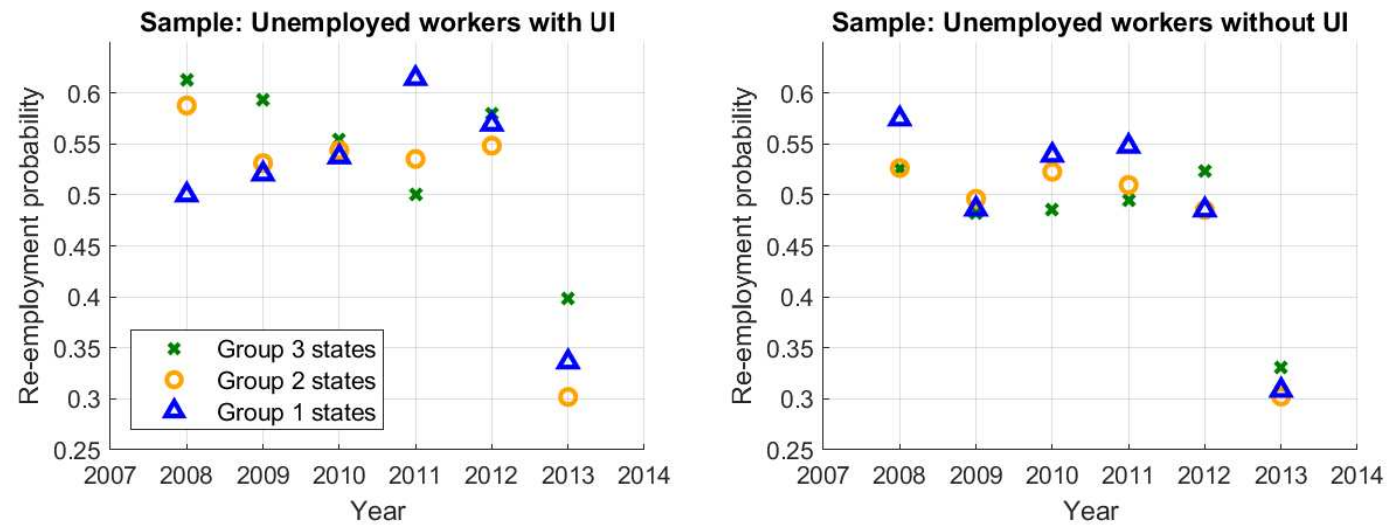

Note: Details of the re-employment measure and interpretation of the pattern can be found in Section 2.2. 


\section{Computational algorithm for the transitional economy}

This subsection gives details on the algorithm used to compute the transition path between two steady states, assuming perfect foresight. The algorithm is similar to Conesa and Krueger (1999) and Nakajima (2012) and described in Ríos-Rull (1999).

- First, solve the worker's problems for each period on the transition path, $t=1,2, \ldots, T$

- Start from the end steady state (calibrated to 2012 target moments). Assuming the transition ends in this steady state.

- Solve the worker's problem in the last period, $t=T$, given the value functions next period are the same as the end steady state, and also given the parameter values and policy for this period. This step gives the worker's value functions and decision rules for $t=T$.

- Solve the worker's problem backward, for $t=T-1, T-2, \ldots, 2$, using the value functions of period $t+1$ as the continuation values. This step assumes that in period $t$ the individuals have perfect foresight for the states of the economy (parameters, policy) in period $t+1$.

- Finally, solve the worker's problem in the first period on the transition path. Check that the value functions and decision rules are close enough to the initial steady state (calibrated to 2005-2007 target moments).

- Next, compute the stationary distribution of workers over individual states

- Start from the initial steady state (calibrated to 2005-2007 target moments).

- Compute the density over individual states in the first period on the transition path, given the distribution in the initial steady state and the decision rules solved in the previous step. Check that all densities sum up to 1 .

- Compute the distribution forward, for $t=2,3, \ldots, T-1$, using the distribution for the period $t-1$ and the decision rules for period $t$. Check at each step to make sure all densities sum up to 1 .

- Finally, compute the distribution in the final period on the transition path. Check that the distribution is close enough to the end steady state (calibrated to 2012 moments). Typically, given that parameters and policy have maintained the same levels for some periods, this convergence is approximated quite well. 


\section{Results for alternative setups in Section 5}

\section{D.1 Model where temp job qualifies for shorter UI benefits}

This subsection contains results for the specification where temp job qualifies for shorter UI entitlement: $J(\underline{w})=2 J / 3$. Section 5.1 provides the rationale for this specification and the discussion of results.

Figure A3: Model where temp job qualifies for shorter UI benefits: Comparison of temp job rejections across steady state economies in 2012.
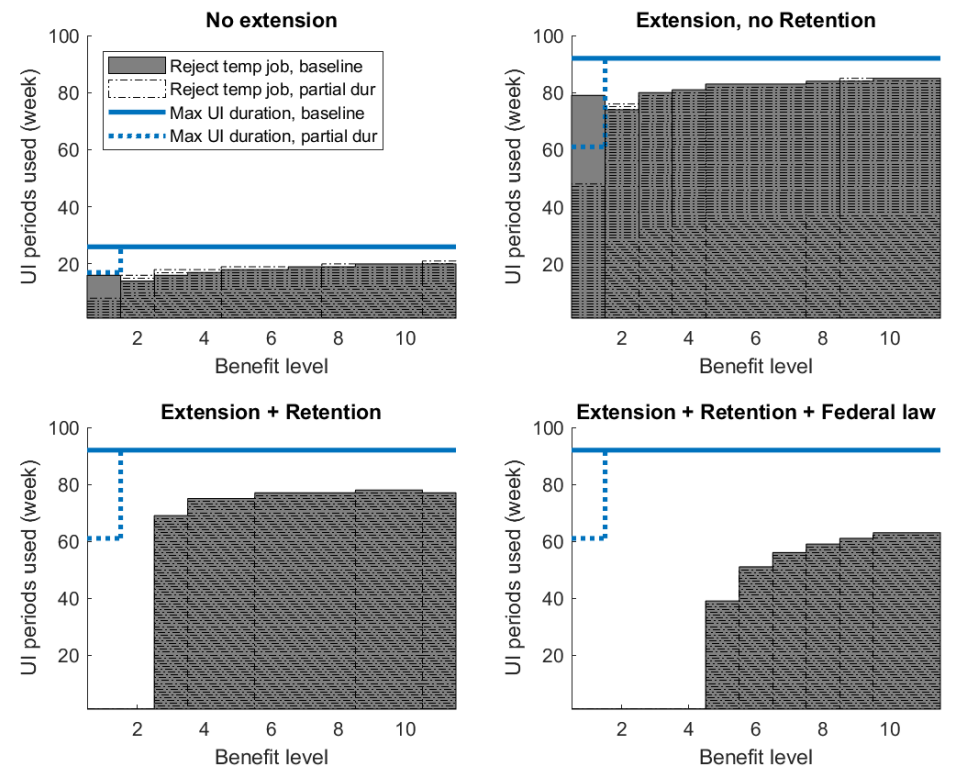

Note: Plots show the decision rule $J_{o b}(\omega, j)$ for each policy scenario. The types of unemployed worker — by benefit level (x-axis) and UI periods used (y-axis) — who reject a temp job offer in a steady state economy are shaded. Sold blocks mark job rejections in the baseline model (the same as Figure 5). Broken blocks mark job rejections in the model with partial UI entitlement. Benefit level $=1$ when old job was temp job, benefit level $=2$ to 11 corresponds to each of the ten bins of regular wages. Blue horizontal line marks the maximum UI entitlement in the economy. 
Figure A4: Model where temp job qualifies for shorter UI benefits:

Comparison of the distribution of unemployed workers across steady state economies in 2012 .
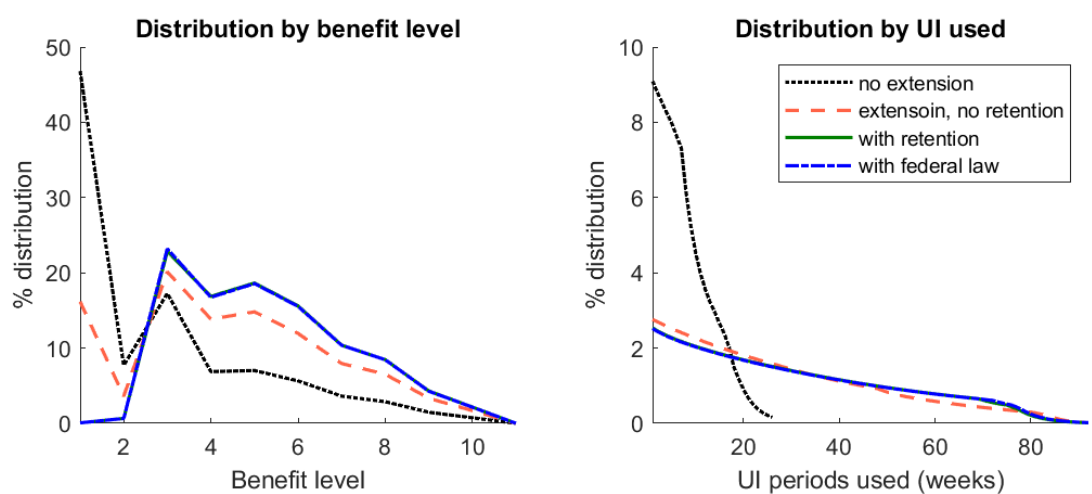

Note: Plots show the percent distribution of unemployed workers for each benefit level (left) or for different levels of UI entitlement used (right). Each line represents the steady state economy with a different policy regime, and the total density on a line sums up to $100 \%$.

Table A1: Model where temp job qualifies for shorter UI benefits: Comparison of steady state economies in 2012.

\begin{tabular}{lcccc}
\hline \hline & No extension & $\begin{array}{c}\text { Extension, } \\
\text { no retention }\end{array}$ & $\begin{array}{c}\text { Extension }+ \\
\text { Retention }\end{array}$ & $\begin{array}{c}\text { Extension }+ \\
\text { Retention }+ \\
\text { Federal law }\end{array}$ \\
\hline Job finding rate(\%) & 12.46 & 5.27 & 12.53 & 17.90 \\
Unemployment rate(\%) & 5.99 & 9.53 & 9.21 & 8.67 \\
\% Workers on temp job & 6.29 & 3.19 & 12.50 & 18.08 \\
\hline
\end{tabular}

Note: Table reports aggregate statistics in each of the four steady state economies. The last economy with extension, retention policy and federal law resembles the economy of 2012 . The other three economies are counterfactuals with alternative policy regimes while holding all other parameters unchanged. 
Figure A5: Model where temp job qualifies for shorter UI benefits: Comparison of transitional economies, 2008-2012.
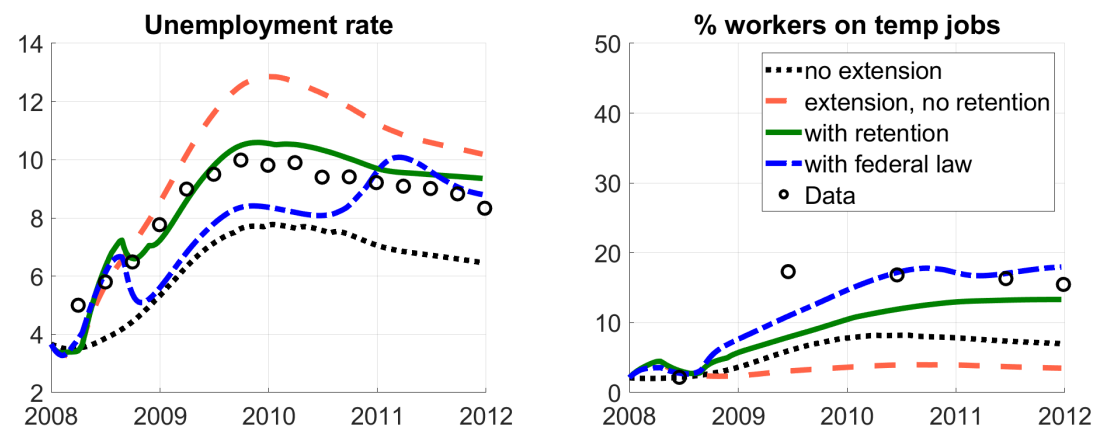

Note: Plot shows the unemployment rate and proportion of workers on temp jobs in the transitional economies from 2008 to 2012 under different policy regimes. Each line represents a different transitional economy. Dots represent data counterparts. 


\section{D.2 Saving and borrowing}

This subsection lays out the worker's problem for the model with saving and borrowing. The results are discussed in Section 5.2.

Model with saving and borrowing The unemployed worker with previous wage $\omega$, at her $j^{\text {th }}$ UI period, and asset holding $a$ chooses next period's asset holding $a^{\prime}$ to maximize the utility from consumption and expected future utility, conditional on her future job choices. Asset position is subject to a lower bound $\underline{a}$, such that $\underline{a}=0$ means there is no borrowing, and $\underline{a}<0$ indicates some borrowing is allowed. Once asset holding choice is made, she consumes UI benefits $(\gamma \omega)$, base consumption $(\underline{c})$, and net asset holding $\left(R a-a^{\prime}\right)$.

$$
\begin{aligned}
U_{t}(\omega, j, a)= & \max _{a^{\prime} \geq \underline{a}} u\left(\gamma \omega+\underline{c}+R a-a^{\prime}\right)+\beta\left(1-\rho_{t}\right) V_{t+1}\left(\omega, j, a^{\prime}\right) \\
& +\beta \rho_{t}\left[\rho_{g, t} \mathbb{E}_{\mathbf{w}} \max \left\{W_{g, t+1}\left(\mathbf{w}, a^{\prime}\right), V_{t+1}\left(\omega, j, a^{\prime}\right)\right\}+\rho_{b, t} \max \left\{W_{b, t+1}\left(\omega, j, 1, a^{\prime}\right), V_{t+1}\left(\omega, j, a^{\prime}\right)\right\}\right]
\end{aligned}
$$

where

$$
V_{t+1}\left(\omega, j, a^{\prime}\right)=\mathbb{1}\left\{j=J_{t}\right\} U_{t}\left(0,0, a^{\prime}\right)+\mathbb{1}\left\{j<J_{t}\right\} U_{t}\left(\omega, j+1, a^{\prime}\right)
$$

Similarly, the worker on regular job with wage $w$ and asset holding $a$ chooses future asset position $a^{\prime} \geq \underline{a}$ to maximize her utility from consumption and expected future utility. Her consumption depends on wage $(w)$ and net asset holding $\left(R a-a^{\prime}\right)$.

$W_{g, t}(\mathbf{w}, a)=\max _{a^{\prime} \geq \underline{a}} u\left(\mathbf{w}+R a-a^{\prime}\right)+\beta\left(1-\delta_{g, t}\right) W_{g, t+1}\left(\mathbf{w}, a^{\prime}\right)+\beta \delta_{g, t}\left[\lambda U_{t+1}\left(\mathbf{w}, 1, a^{\prime}\right)+(1-\lambda) U_{t+1}\left(0,0, a^{\prime}\right)\right]$

The worker on temp job with previous UI benefit indexed by $\omega, j^{\text {th }}$ periods of UI benefit used during the previous unemployment spell, $j w$ periods worked on current job, and asset holding $a$ chooses future asset position $a^{\prime}$ to maximize the utility from consumption and expected future utility, taking as given her choice of UI segment (new or old) if available. Her consumption consists of wage 
income $(\underline{w})$ and net asset holding $\left(R a-a^{\prime}\right)$.

$$
\begin{aligned}
& W_{b, t}(\omega, j, j w, a)=\max _{a^{\prime} \geq \underline{a}} u\left(\underline{w}+R a-a^{\prime}\right)+\beta\left(1-\delta_{b, t}\right) W_{b, t+1}\left(\omega, j, j w+1, a^{\prime}\right) \\
& +\left\{\begin{array}{l}
(\text { recession, before July 2010) } \\
\beta \delta_{b, t}\left[Q_{s}(\omega, j w) U_{t+1}\left(\underline{w}, 1, a^{\prime}\right)+\left(1-Q_{s}(\omega, j w)\right) U_{t+1}\left(\omega, j, a^{\prime}\right)\right] \\
(\text { recession, after July 2010) } \\
\beta \delta_{b, t}\left[Q_{s}(\omega, j w) \max \left\{U_{t+1}\left(\underline{w}, 1, a^{\prime}\right), U_{t+1}\left(\omega, j, a^{\prime}\right)\right\}+\left(1-Q_{s}(\omega, j w)\right) U_{t+1}\left(\omega, j, a^{\prime}\right)\right] \\
(\text { non-recession) } \\
\beta \delta_{b, t}\left[Q_{s}(\omega, j w) U_{t+1}\left(\underline{w}, 1, a^{\prime}\right)+\left(1-Q_{s}(\omega, j w)\right) U_{t+1}\left(0,0, a^{\prime}\right)\right]
\end{array}\right.
\end{aligned}
$$

where $Q_{s}$ is as defined before by Equation (12).

I discretize the asset grid $\left[\underline{a}, a_{\max }\right]$ with a step size of 0.05 . I set the upper bound $a_{\max }=1.0$ and check that it does not bind. The lower bound $a_{\min }$ is set at 0 (no borrowing) or -0.2 (some borrowing). Interest rate is set at $0.06 \%$ weekly or $3 \%$ per annum. 
Results in steady state 2012 Results are discussed in Section 5.2. I show the results with both saving and borrowing $\left(a_{\min }=-0.2\right)$. When borrowing is not allowed $\left(a_{\min }=0\right)$ the results are similar.

Figure A6: Saving and borrowing $\left(a_{\min }=-0.2\right)$ :

Comparison of temp job rejections across steady state economies in 2012.
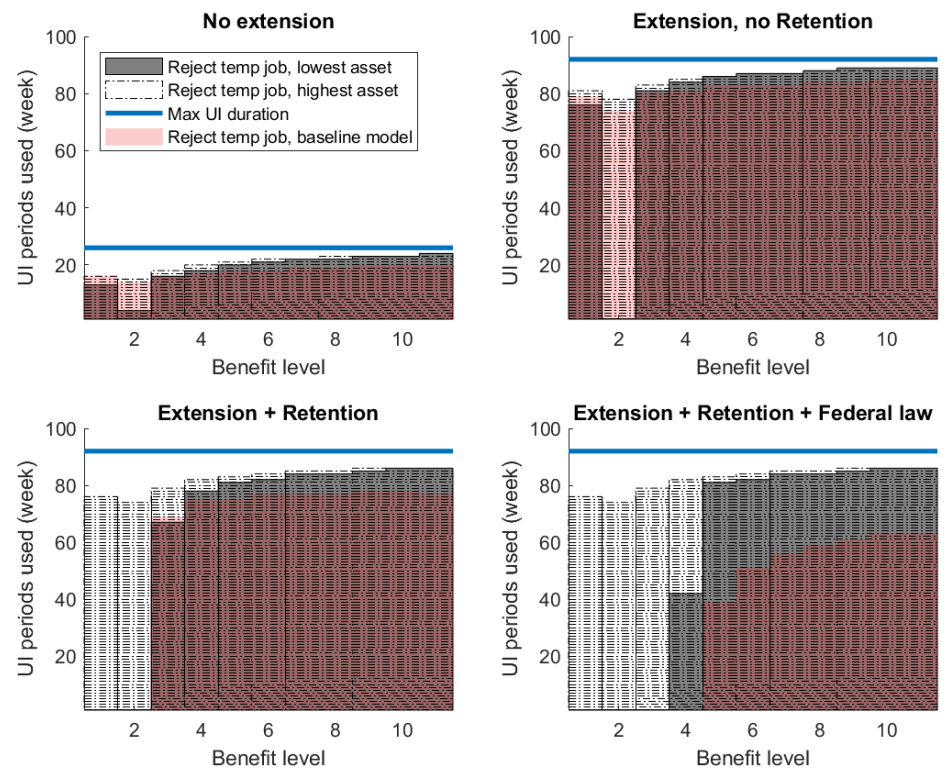

Note: Plots show the decision rule $J_{o b}(\omega, j, a)$ for each policy scenario. The types of unemployed worker - by benefit level (x-axis) and UI periods used (y-axis) — who reject a temp job offer in a steady state economy are shaded. Sold grey blocks mark job rejections for unemployed workers with the lowest asset level; broken blocks mark job rejections for those with the highest asset level. Semi-transparent red blocks mark job rejections in the baseline model without saving and borrowing (the same as Figure 5). Benefit level $=1$ when old job was temp job, benefit level $=2$ to 11 corresponds to each of the ten bins of regular wages. Blue horizontal line marks the maximum UI entitlement in the economy.

Table A2: Saving and borrowing $\left(a_{\min }=-0.2\right)$ :

Comparison of steady state economies in 2012.

\begin{tabular}{lcccc}
\hline \hline & No extension & $\begin{array}{c}\text { Extension, } \\
\text { no retention }\end{array}$ & $\begin{array}{c}\text { Extension }+ \\
\text { Retention }\end{array}$ & $\begin{array}{c}\text { Extension }+ \\
\text { Retention }+ \\
\text { Federal law }\end{array}$ \\
\hline Job finding rate(\%) & 10.04 & 5.07 & 8.08 & 8.57 \\
Unemployment rate(\%) & 7.96 & 9.86 & 10.63 & 10.46 \\
\% Workers on temp job & 7.26 & 3.18 & 8.47 & 8.99 \\
\hline
\end{tabular}

Note: Table reports aggregate statistics in each of the four steady state economies. The last economy with extension, retention policy and federal law is calibrated to the economy of 2012. The other three economies are counterfactuals with alternative policy regimes while holding all other parameters unchanged. 
Figure A7: Saving and borrowing $\left(a_{\min }=-0.2\right)$ :

Comparison of the distribution of unemployed workers across steady state economies in 2012.

(a) Bottom 5 asset levels
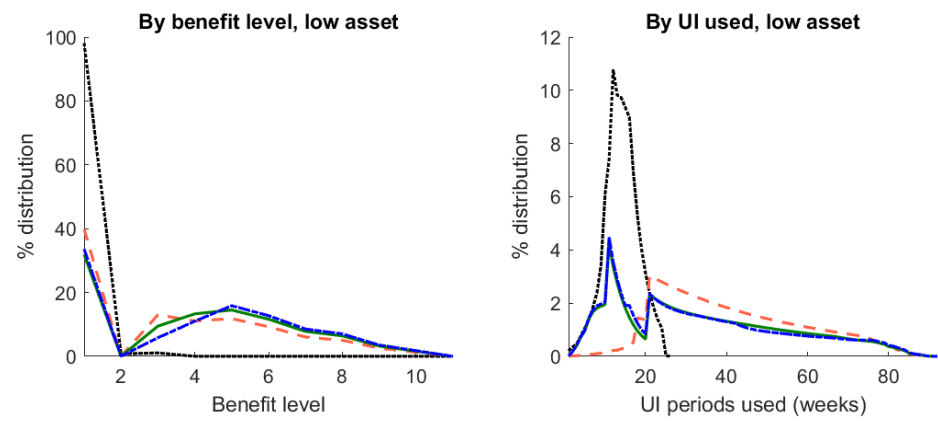

(b) Top 5 asset levels
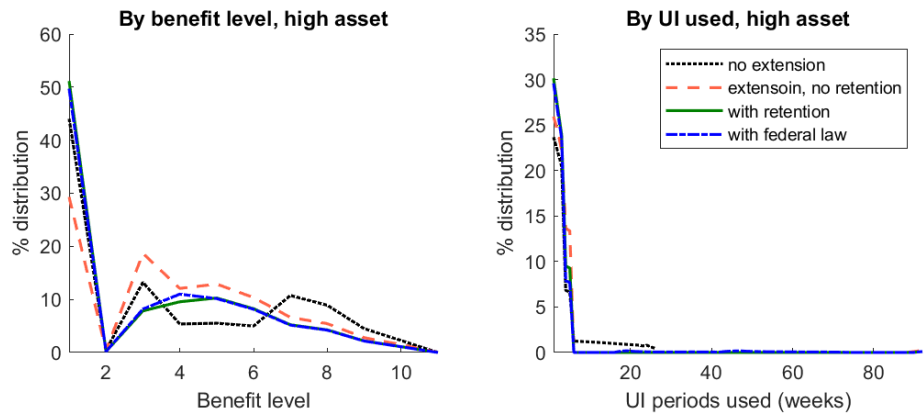

Note: Plots show the percent distribution of unemployed workers for each benefit level (top) or for different levels of UI entitlement used (bottom). Distribution is plotted by asset levels: left two plots are for unemployed workers in the bottom 5 asset levels, right two plots are for those in the top 5 asset levels. Each line represents the steady state economy with a different policy regime. Distribution is presented as percent density on a line so the total density on a line sums up to $100 \%$. 


\section{D.3 Job quits}

This subsection contains results for the specification where workers on temp jobs are allowed to quit and still collect benefits. Section 5.3 provides the rationale for this specification and the discussion of results.

Figure A8: Job quits:

Comparison of temp job rejections across steady state economies in 2012.
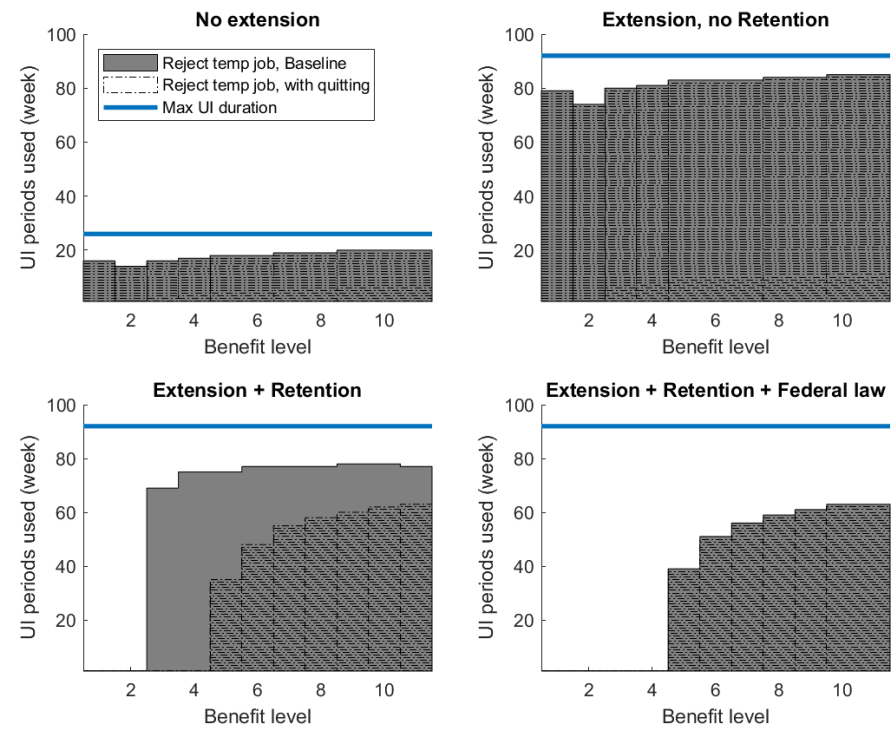

Note: Plots show the decision rule $J_{o b}(\omega, j)$ for each policy scenario. The types of unemployed worker — by benefit level (x-axis) and UI periods used (y-axis) — who reject a temp job offer in a steady state economy are shaded. Sold blocks mark job rejections in the baseline model (the same as Figure 5). Broken blocks mark job rejections in the model with the option to quit. Benefit level $=1$ when old job was temp job, benefit level $=2$ to 11 corresponds to each of the ten bins of regular wages. Blue horizontal line marks the maximum UI entitlement in the economy.

Table A3: Job quits:

Comparison of steady state economies in 2012.

\begin{tabular}{lcccc}
\hline \hline & No extension & $\begin{array}{c}\text { Extension, } \\
\text { no retention }\end{array}$ & $\begin{array}{c}\text { Extension }+ \\
\text { Retention }\end{array}$ & $\begin{array}{c}\text { Extension }+ \\
\text { Retention }+ \\
\text { Federal law }\end{array}$ \\
\hline Job finding rate(\%) & 9.79 & 5.04 & 18.07 & 17.90 \\
Unemployment rate(\%) & 7.11 & 9.60 & 9.12 & 8.67 \\
\% Workers on temp job & 5.71 & 2.94 & 13.5 & 18.08 \\
\hline
\end{tabular}

Note: Table reports aggregate statistics in each of the four steady state economies. The last economy with extension, retention policy and federal law resembles the economy of 2012. The other three economies are counterfactuals with alternative policy regimes while holding all other parameters unchanged. 


\section{D.4 Wage dispersion in temp jobs}

This subsection contains results for the specification where temp job offers three possible levels of wages: $\{0.3,0.35$ (baseline value) 0.37$\}$, with probabilities: $[0.25,0.5,0.25]$. The rest of the parameters are kept the same as in the baseline. Section 5.3 provides the rationale for this specification and the discussion of results.

Figure A9: Wage dispersion in temp jobs:

Comparison of temp job rejections across steady state economies in 2012.
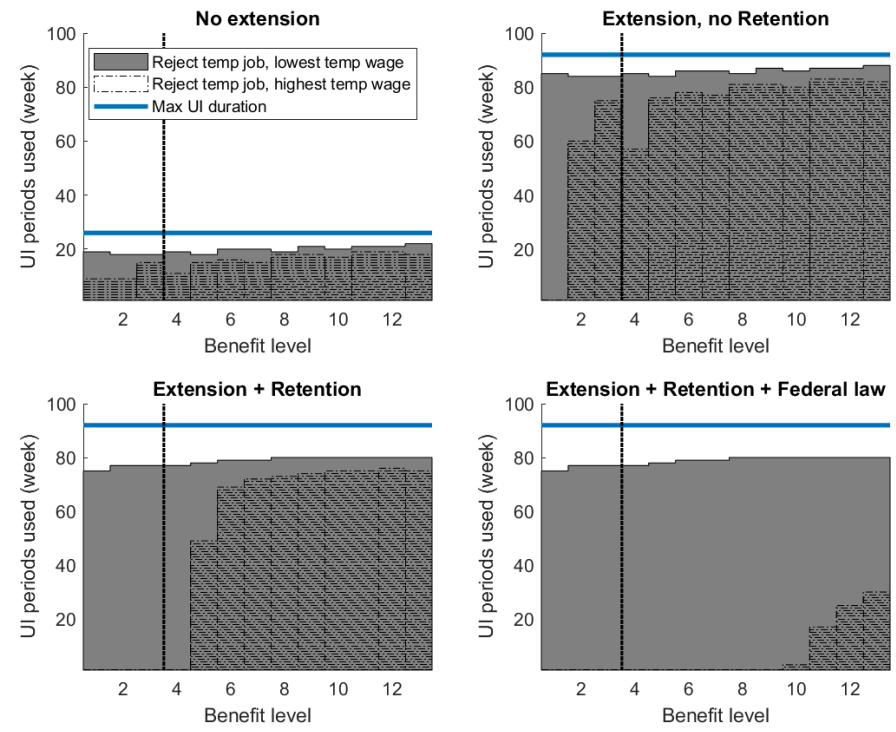

Note: Plots show the decision rule $J o b_{b}(\omega, j)$ for each policy scenario. The types of unemployed worker - by benefit level (x-axis) and UI periods used (y-axis) - who reject a temp job offer in a steady state economy are shaded. Sold grey blocks mark rejections of the lowest temp wage offer; broken blocks mark rejections of the highest temp wage offer. Benefit level $=1,2,3$ when old job was temp job, benefit level $>=4$ corresponds to each of the ten bins of regular wages. Blue horizontal line marks the maximum UI entitlement in the economy. The dotted vertical line marks previous job: to the left are unemployed workers previously on temp jobs (wage levels $0.3,0.35,0.37$ ); to the right are those previously on regular jobs 
Table A4: Wage dispersion in temp jobs: Comparison of steady state economies in 2012.

\begin{tabular}{lcccc}
\hline \hline & No extension & $\begin{array}{c}\text { Extension, } \\
\text { no retention }\end{array}$ & $\begin{array}{c}\text { Extension }+ \\
\text { Retention }\end{array}$ & $\begin{array}{c}\text { Extension }+ \\
\text { Retention }+ \\
\text { Federal law }\end{array}$ \\
\hline Job finding rate(\%) & 10.04 & 5.23 & 7.57 & 14.62 \\
Unemployment rate(\%) & 7.26 & 9.59 & 11.65 & 10.58 \\
\% Workers on temp job & 6.20 & 3.18 & 8.95 & 18.48 \\
\hline
\end{tabular}

Note: Table reports aggregate statistics in each of the four steady state economies. The last economy with extension, retention policy and federal law resembles the economy of 2012. The other three economies are counterfactuals with alternative policy regimes while holding all other parameters unchanged. 


\section{D.5 The effect of human capital}

This subsection contains regression results of hourly wages or monthly earnings on short-term or long-term human capital. Results are discussed in Section 5.3. Long-term human capital is proxied by potential experience (in months) defined as the difference between a person's age at a time and years of education. Short-term human capital is the observed cumulative months worked by a person at the time.

Table A5: Regression results of wage or earning on accumulated short-term or long-term human capital.

\begin{tabular}{|c|c|c|}
\hline \multirow[b]{2}{*}{ Independent Variables } & \multicolumn{2}{|c|}{ Dependent Variables } \\
\hline & Hourly wage & Monthly earning \\
\hline Long-term human capital & $0.051^{* *}$ & $15.2^{* *}$ \\
\hline Short-term human capital & $0.031^{* *}$ & $9.7^{* *}$ \\
\hline \multicolumn{3}{|c|}{$\begin{array}{l}\text { Note: Table reports coefficients hourly wage or monthly earnings regressions. Each entry is result } \\
\text { from one regression. Each column is a different dependent variable, each row is a different inde- } \\
\text { pendent variable. SIPP } 2008 \text { panel, restricted to individuals ages } 20 \text { to } 64 \text { at time of survey. All } \\
\text { regressions include controls for demographics (race, age, educational attainment), industry of work } \\
\text { dummies, monthly unemployment rate of state of residence, whether the individual has had an } \\
\text { unemployment spell. Standard errors clustered at the individual level. } \\
{ }^{* *} p<5{ }^{*} p<10 \text {. }\end{array}$} \\
\hline
\end{tabular}

